\title{
LUT
}

University

\section{A GIS-based Method to Identify Potential Sites for Pumped Hydro Energy Storage - Case of Iran}

Ghorbani Narges, Makian Hamed, Breyer Christian

This is a Author's accepted manuscript (AAM) version of a publication published by Elsevier

in Energy

DOI: $\quad 10.1016 /$ j.energy.2018.12.073

Copyright of the original publication: (c) 2018 Elsevier Ltd.

Please cite the publication as follows:

Narges Ghorbani, Hamed Makian, Christian Breyer, A GIS-based Method to Identify Potential Sites for Pumped Hydro Energy Storage - Case of Iran, Energy (2018), doi: 10.1016/j. energy.2018.12.073

This is a parallel published version of an original publication. This version can differ from the original published article. 


\section{Accepted Manuscript}

A GIS-based Method to Identify Potential Sites for Pumped Hydro Energy Storage

- Case of Iran

Narges Ghorbani, Hamed Makian, Christian Breyer

PII:

S0360-5442(18)32439-3

DOI:

10.1016/j.energy.2018.12.073

Reference:

EGY 14326

To appear in:

Energy

Received Date:

10 August 2018

Accepted Date:

11 December 2018

Please cite this article as: Narges Ghorbani, Hamed Makian, Christian Breyer, A GIS-based Method to Identify Potential Sites for Pumped Hydro Energy Storage - Case of Iran, Energy (2018), doi: 10.1016/j.energy.2018.12.073

This is a PDF file of an unedited manuscript that has been accepted for publication. As a service to our customers we are providing this early version of the manuscript. The manuscript will undergo copyediting, typesetting, and review of the resulting proof before it is published in its final form. Please note that during the production process errors may be discovered which could affect the content, and all legal disclaimers that apply to the journal pertain. 


\title{
A GIS-based Method to Identify Potential Sites for Pumped Hydro Energy Storage - Case of Iran
}

\author{
Narges Ghorbani ${ }^{1, *}$, Hamed Makian ${ }^{2}$ and Christian Breyer ${ }^{1}$ \\ ${ }^{1}$ Lappeenranta University of Technology, Skinnarilankatu 34, 53850 Lappeenranta, Finland \\ ${ }^{2}$ Geological Survey \& Mineral Exploration of Iran, Azadi Square, Tehran, Iran \\ *Corresponding author, E-mail address: narges.ghorbanikoltapeh@lut.fi
}

\begin{abstract}
Pumped hydro energy storage (PHES) is the most widespread and mature utility-scale storage technology currently available and it is likely to remain a competitive solution for modern energy systems based on high penetration of solar PV and wind energy. This study estimates the technical potential of PHES in Iran through automatised GIS-based models based on four topologies. Two topologies focus on the transformation of existing reservoirs while the third topology which is developed based on permanent rivers of the country offers more alternative sites. The fourth topology assesses the potential of seawater PHES plants as a potential solution for regions characterised by freshwater scarcity. The TOPSIS method is applied to the discovered feasible sites to integrate an economic sensitivity into the evaluation process. Results show that Iran has a favourable topography for PHES and the technical potential of the studied topologies reaches up to $5108 \mathrm{GWh}$ from 250 discovered sites, compared to the existing 5.1 GWh PHES capacity, while a maximum distance of $20 \mathrm{~km}$ is considered between reservoirs of a PHES plant.
\end{abstract}

\section{Keywords}

Geographical information system, Pumped hydro energy storage, Renewable energy, Iran, TOPSIS method, Seawater PHES

\section{Introduction}

To meet the world's growing energy demand in a sustainable manner that fulfils the Paris Agreement [1] and mitigates climate change, large-scale deployment of renewable energy (RE) is inevitable. Studies show a power system based on $100 \%$ RE is a technically feasible and economically viable solution for the future energy system, globally [2,3,4]. In 2017, renewables accounted for $70 \%$ of newly installed power capacities, while $84 \%$ of that were variable solar PV and wind energy [5]. Solar and wind offer considerable global potential for massive implementation and are expected to be the most sustainable and cost competitive sources of energy generation, which will dominate the future energy system $[2,3,6,7,8]$. To support the integration of variable RE, storage technologies play a crucial role to solve the challenges of intermittent generation and mismatch of supply and demand, during generation scarcity and excess supply situations. Pumped hydro energy storage (PHES) is the most widespread and mature utility-scale storage technology currently available $[9,10]$. Other large-scale storage technologies like compressed air energy storage (CAES) [11] or power-to-gas (PtG) [12] are commercially available, but are more expensive for diurnal storage. Batteries can cover diurnal 
storage demand and have experienced utility-scale installations in the recent years [13], but they have limited ability for providing energy storage over the long term. However, studies show batteries to be the most relevant type of storage technologies in an energy system based on RE and they are complemented by PHES and PtG, which can cover the storage demand all year round $[2,3]$.

A PHES facility typically involves two reservoirs located at different elevations and connected with reversible pumps/generators. During low-demand period and surplus generation, water is pumped from the lower reservoir to the upper reservoir storing electricity by converting power into gravitational potential. Such stored energy can be reconverted to electricity by releasing the stored water through a turbine during high-demand and low-generation periods. The major difference between PHES and a conventional hydropower plant is that the flow is bidirectional for PHES, which makes the system capable of storing electricity (Fig. 1).

In 2017, the total global capacity of storage technologies reached $153 \mathrm{GW}$, out of which $96 \%$ was PHES [5]. PHES systems offer a good round-trip efficiency (70-80\%) [14], a long lifetime (50 - 100 years) [15,16] and good to very good response (minutes to seconds) $[17,18]$, depending on the age and design. PHES is currently much more mature and cost-effective than other alternative storage technologies, but in the future other storage options are most likely to be lower in cost [2,3]. However, PHES can play a critical role alongside other storage technologies in an energy system with high penetration of RE. PHES can complement batteries to balance short-term storage demand while PtG covers seasonal storage [2,3]. The cost of a PHES power plant is highly dependent on the location and characteristics of the site. In recent years, finding a suitable location to construct PHES has become an obstacle to development in some countries and this has raised doubts about contribution of this mature storage option to future energy systems [19].

Therefore, the intention of this study is to develop a method, based on Geographic Information System (GIS) tools, to search a selected terrain automatically in order to detect suitable locations for construction of PHES. Furthermore, the model is applied to estimate the potential of seawater PHES that has been considered in a few research works while it holds opportunity for contributing to the future energy system especially for regions characterised by freshwater scarcity [20]. In seawater PHES, the sea is utilised as the lower reservoir, which guarantees water supply and avoids construction of the lower reservoir. There is one seawater PHES worldwide which was constructed in Okinawa, Japan in 1999 [21]. About two decades operation of this plant and detailed technical studies have proven that the technological and environmental concerns regarding the use of seawater in PHES could be properly addressed through correct positioning and selection of the equipment [22].

The model, which is developed in this study, is applicable to any selected region and is able to detect potential PHES sites for following four topologies:

- Linking pairs of existing reservoirs to form a PHES site.

- Scanning a broad geographical area (in this study within a $20 \mathrm{~km}$ buffer) around all reservoirs to identify suitable spots for hosting the second reservoir.

- Scanning the surrounding area of all river ways to find prospective areas for the second reservoir. 
- Searching the vicinity of a given coastline to detect suitable locations for construction of the upper reservoir while the sea is considered as the lower reservoir

The model is applied on a country level and for the case of Iran. Iran is well suited since existing reservoirs, rivers and the country's coastlines (Caspian Sea in the north and Persian Gulf and Gulf of Oman in the south) in combination with an appropriate topography constitute the PHES potential. Additionally, the energy transition ahead with dominating solar PV and complementing wind energy in the energy mix [23] may create demand.

The model is intended to investigate a broad geographical scale in the country to discover the suitable areas where there are water resources and favourable topography for construction of PHES. In the next step environmental and land-cover constraints are applied to the detected sites to eliminate infeasible sites. Finally, the Multi Criteria Decision Making (MCDM) technique is carried out for these feasible areas to define the most prospective sites. The MCDM method, which is used in this study, is Technique for Order Preference by Similarity to Ideal Solution (TOPSIS). To evaluate the suitable sites, 7 criteria including head, area and distance of the site to the grid network are selected.
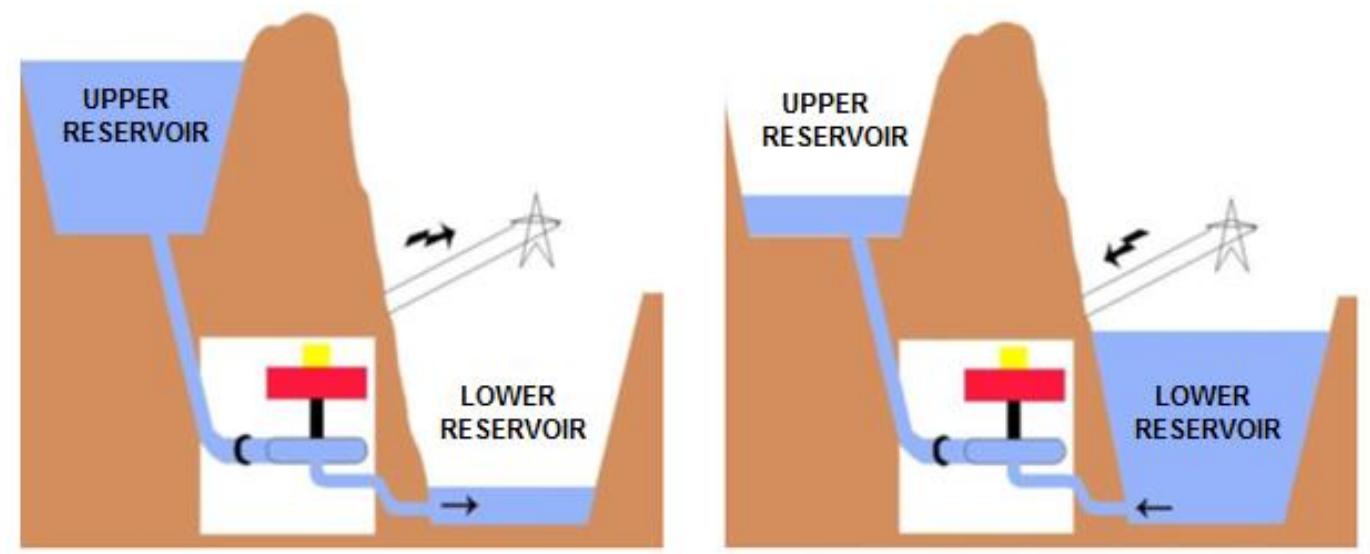

Fig. 1. Schematic of a pumped hydro energy storage power plant in turbine mode (left) and pump mode (right) [24].

\section{Case study Iran}

Iran is located in West Asia at latitude of $\mathrm{N} 25^{\circ} 3^{\prime}$ to $39^{\circ} 47^{\prime}$ and longitude of E44 $4^{\circ} 5^{\prime}$ to $63^{\circ} 18^{\prime}$. The total area of the country is about 1.65 million $\mathrm{km}^{2}$ and its elevation ranges from 28 meters in the Caspian Sea to 5610 meters on Mount Damavand. Although Iran is located in an arid and semi-arid region, hydropower is the major RE contributor to the generated power in the country. Hydropower contributes $5 \%$ of the total produced electricity in Iran, while the share of solar and wind is less than $0.1 \%$ [25]. Due to the country's dry climate and necessity of harnessing the limited water resources, dam construction has a long history of more than 2000 years in Iran [26]. At present, 647 dams are operated and 682 dams are under construction or being surveyed for construction [27]. In recent years, Iran has faced a series of serious droughts, and building new dams has not only caused more environmental damage [28], but also from an electricity point of view it was not efficient, since most of the hydropower plants remain underutilised or have been decommissioned [29]. Therefore, conventional hydropower will not 
be able to gain a significant role in the country's future energy system [30,23]. On the other hand, Iran is highly endowed with solar and wind energy [31,32] and it is estimated that they will be the most efficient sources of energy for a sustainable and secure energy system in the future [30,23]. Therefore, transformation of conventional hydropower plants and dams into PHES facilities and considering unconventional PHES such as seawater PHES would be an opportunity to utilise the existing hydropower facilities and water resources more effectively (since PHES does not need direct flow) and also to support the penetration of variable solar and wind energy into the national electricity grid.

Therefore, the intention of the first 2 studied topologies in the present work is to estimate the country's PHES potential through a transformation of existing reservoirs to PHES facilities. While T6 discovers more locations for PHES sites in the vicinity of permanent rivers in the country, offering more alternatives for decision makers regarding site selection. Finally, T4 assesses the potential of seawater PHES as an innovative plant that suits the geographical characteristics of Iran, having $3000 \mathrm{~km}$ coastline and the country's dry climate and inefficient freshwater availability.

\section{Literature review}

PHES is the most mature utility-scale storage option currently available and is more likely to play a crucial role in future energy systems with high shares of variable RE. In the recent years, small-scale PHES schemes have been studied more deeply due to their lower environmental impact. Small-scale PHES with capacities ranging from $1 \mathrm{MW}$ to $50 \mathrm{MW}$ (depending on the country's classification) can play an important role in balancing local level energy systems and shaving the peak demand, particularly when a well distributed electricity grid is not available [33]. Rogeau et al. [33] estimated the potential of a proposed small PHES system in France. The methodology took advantage of natural waterbodies and terrain depression to overcome the disadvantage of small PHES associated with high capital costs compared to small-scale storage capacities. The study estimated a potential of 14-33 GWh depending on the considered natural features. Soha et al. [34] considered artificial landscape features such as artificial reservoirs and open-cast mines, in addition to natural waterbodies, as an opportunity for smallscale PHES deployment in middle mountain areas of Europe. The methodology was applied to an area encompassing $1324 \mathrm{~km}^{2}$ in North Hungary, where all the mentioned landscape features are present. The result showed that the sample area has a potential of storing about $1700 \mathrm{MWh}$ of energy theoretically. Although small-scale PHES has lower environmental impact, it can be only considered as a storage option locally and regionally. Arántegui et al. [35] claim, that for national and continental solutions, large-scale PHES is the only feasible solution that could offer a significant amount of energy at affordable prices.

A GIS-based approach is deployed through different topologies over some regions to assess the potential of large-scale PHES systems. Table 1 presents seven possible topologies for an assessment of the PHES potential that are classified by Arántegui et al. [35]. Topology 1 (T1) was applied by U.S Department of Energy to assess the potential of PHES in the United States [36]. The study focused on finding two waterbodies to form a PHES site. The waterbodies have to meet the identified criteria, including maximum distance and minimum elevation difference. Four types of waterbodies were considered in this research: existing conventional hydropower dams, non-powered dams, greenfield hydropower plants and natural waterbodies. The study is limited to identify sites with an existing reservoir, and sites where topography is suitable for building a reservoir, it is recommended for future studies to enhance and expand the research. 
For Europe, a research by the European Commission's Joint Research Centre examined the potential of large-scale PHES on a country level [37]. The study includes two topologies (T1 and T2) for the construction of the PHES system. T1 focused on linking pairs of existing artificial reservoirs to form PHES sites. In T2, sites with one existing reservoir and a suitable flat area for building the second reservoir were considered. A similar methodology considering just T2 is applied to another study to examine the potential for transformation of existing reservoirs to PHES facilities in Turkey [38]. The study investigated surrounding areas of reservoirs in order to identify flat areas offering suitable topography for hosting the second reservoir. Lu and Wang [39] investigated Tibet's potential for PHES through T1 and T2. However, for T2 due to Tibet's rough terrain, instead of detecting a flat area for building the second reservoir, the model had been adjusted to select valleys to discover more suitable spots. $\mathrm{Lu}$ et al. [40] undertook a GIS-based methodology across South Australia to analyse the potential of off-river PHES systems, which have less environmental impact compared to the systems connected to waterbodies. The model was designed to identify two types of sites, drygully and turkey's nest and results showed a potential of $276 \mathrm{GWh}$. The study argues that the water can be conveyed from water resources in the vicinity or by truck.

Some large-scale PHES studies investigated a small geographical zone. Connolly et al. [41] identified through a Triangulated Irregular Network (TIN) model, feasible PHES sites over an area of $800 \mathrm{~km}^{2}$ in Ireland. The main challenge that has been stated as an obstacle to the deployment of the model over a larger zone was the consumed time for implementing the model. For an area of $800 \mathrm{~km}^{2}$ the approximate computation time had been 20 weeks, but by removing parts of the area that did not meet the defined criteria, the computation time could be reduced to 6-10 days. Ahmadi and Shamsai [42] investigated the surrounding areas of a reservoir in the central part of Iran to identify suitable sites to construct an upper reservoir. Different data layers have been used to consider grid situation, road accessibility and detailed geological characteristic of the selected site.

Unconventional PHES plants such as seawater PHES have been studied recently. Since seawater PHES uses the sea as its lower reservoir, this plant has potential to mitigate environmental impacts of PHES associated with construction of the reservoirs and using freshwater resources [43]. Seawater PHES schemes comprise a solution for regions with insufficient freshwater for example regions in Africa and Middle East [44, 45] in order to integrate PHES into their energy systems and benefit from this mature utility-scale storage system and increase renewable energy penetration. Portero et al. [20] presented a hybrid windhydro system using a seawater PHES located on the Gran Canaria island, considering the problem of low freshwater reserves in the Canary Islands. The result of incorporation of PHES was $29 \%$ higher contribution in electricity generation compared to a wind only system. Katsaprakakis et al. [22] indicated through a detailed technical study that seawater PHES with a special design that avoids corrosion and leakage effect, can provide a guaranteed choice for development of renewable energy in regions with low annual rainfalls. However, there are limited studies focused on seawater PHES and especially its potential estimation in a region [46]. Kotiuga et al. [47] undertook a pre-feasibility study to discover potential sites for a 1000 MW PHES in Saudi Arabia. They considered the feasibility of construction a seawater PHES as an alternative and discovered the coastline from Aqaba to the Yemen border. 27 cross sections from the sea were investigated through a manual process and using Google Earth for a maximum head of $800 \mathrm{~m}$ and the ratio of distance between reservoirs to head $(\mathrm{L} / \mathrm{H})$ less than 20.

Among above mentioned studies only [37] and [39] have derived the PHES potential on a country level based on 2 topologies (both $\mathrm{T} 1$ and $\mathrm{T} 2$ ). [37] investigated the existing reservoirs 
while the model used in [38] focused on topography and did not consider the water availability. Regarding seawater PHES, only [47] discovered the potential sites of a country but through a manual procedure using Google Earth for the case of Saudi Arabia. In the present study, a GISbased model written in Python which is applicable to any selected country and region is used to detect automatically the PHES potential sites based on four topologies. The model includes all potential waterbodies of the studied region and covers T1, T2, T4 and T6 as described in Table 1.

Table1. Possible topologies for assessing large-scale PHES [35,37].

\begin{tabular}{|c|c|}
\hline Topology & Potential assessment approach \\
\hline $\mathrm{T} 1$ & $\begin{array}{l}\text { Linking two existing reservoirs (artificial reservoirs or lakes) with a penstock, and adding a } \\
\text { powerhouse to transform them to a PHES scheme. }\end{array}$ \\
\hline $\mathrm{T} 2$ & $\begin{array}{l}\text { Transformation of one existing lake or reservoir to PHES by detecting a suitable site for a } \\
\text { second reservoir. The second reservoir could be on a flat area (by digging or building shallow } \\
\text { dams), on a depression or on a valley. }\end{array}$ \\
\hline $\mathrm{T} 3$ & $\begin{array}{l}\text { A greenfield PHES based on a suitable topographical context: either valleys, which can be } \\
\text { closed with a dam, depressions, hill tops, which could be slashed, etc. This topology is broader } \\
\text { i.e. neither based on existing lakes or reservoirs nor assuming a flat area for building the second } \\
\text { reservoir. }\end{array}$ \\
\hline T4 & A greenfield PHES that uses the sea as the lower reservoir and a new nearby reservoir. \\
\hline T5 & $\begin{array}{l}\text { Multi-reservoir systems including both PHES and conventional hydropower. For example, } \\
\text { linking the reservoirs of a conventional hydropower with a lake or an artificial reservoir to add } \\
\text { PHES scheme to the system. }\end{array}$ \\
\hline T6 & $\begin{array}{l}\text { The lower reservoir is basically a large river providing sufficient inflow into the PHES system. } \\
\text { An example is the Jochenstein-Riedl PHES, where the Danube acts as the lower reservoir. }\end{array}$ \\
\hline $\mathrm{T} 7$ & $\begin{array}{l}\text { Use of an abandoned mine pit as the basis for the PHES. The methodology to be used would be } \\
\text { similar to the Topology } 2 \text { case. An example is the old coal mine of As Pontes, in Spain. }\end{array}$ \\
\hline
\end{tabular}

This study proposes a flexible GIS-based model written in Python, which can cover the assessment of PHES potential for a variety of topologies. The automatised procedure of the model enables accurate topographical analyses in a broad geographical area, on a country and global level. In this study, the model is applied for the case of Iran as a case study, but it is applicable to any selected region by simply changing the model's input database into the corresponding database of the target region. In this study in addition to the existing reservoirs, all river ways of the country are assessed to discover potential sites for PHES for T6. This study, to the knowledge of the authors, is the first research to assess the potential of seawater PHES at the whole coastal area of a country through an automatised GIS-based model. In this study, in order to integrate economic sensitivity into the evaluation process, 7 criteria which highly affect the cost of the PHES projects are selected and the TOPSIS method are applied to the discovered feasible sites. The potential of the large-scale PHES for 4 topologies which covers all water bodies of the country is discovered and the potential sites are ranked according to their economic feasibility.

\section{Methodology}

The proposed methodology consists of two GIS-based models, which discover prospective PHES sites in a selected region for four topologies, referred as T1, T2, T4 and T6 in Table 1. 


\subsection{Topology 1}

The GIS model detects pairs of existing reservoirs, which fulfil defined constraints to form a PHES plant. The constraints include a maximum distance of $20 \mathrm{~km}$, and a minimum elevation difference of $150 \mathrm{~m}$ between reservoirs. The model is fed with geo-referenced reservoirs database and the digital elevation model (DEM) of the country. A buffer of $20 \mathrm{~km}$ radius is placed around each reservoir to detect all reservoirs located inside the buffer that satisfy the distance criterion. The next step is applying the minimum head restriction on the detected reservoirs. Therefore, reservoirs with elevation of $150 \mathrm{~m}$ above or below the studied reservoirs are selected as potential second reservoirs to be linked, forming a PHES plant. Figure 3 (left) shows the flowchart of the applied model.

\subsection{Topology 2}

In this topology for the transformation to PHES scheme, an existing reservoir is considered as a potential lower reservoir and its surrounding area is analysed by the model to discover a flat area (slope less than 5\%) for building the upper reservoir. According to the definition of T2 in Table 1, the upper reservoir can be constructed by blocking a valley or digging a flat area. The former methodology was applied to Tibet due to its rough terrain [39] and the latter methodology was used for the case of Turkey [38]. In the present study, selecting a flat area approach was considered due to being more appropriate for Iran and having less environmental impacts, compared to closing a valley with a dam [37].

The applied constraints regarding the maximum distance between reservoirs and the minimum head of the prospective PHES plants are similar to T1 constraints. Moreover, in this topology, a minimum $1,000,000 \mathrm{~m}^{3}$ for the capacity of the new reservoir is considered. To satisfy this, a minimum area of 70,000 $\mathrm{m}^{2}$ was selected for the proposed locations, considering $50,000 \mathrm{~m}^{2}$ for the area of the reservoir and $20,000 \mathrm{~m}^{2}$ for civil works, while depth of the reservoir is assumed to be $20 \mathrm{~m}[35,38]$.

\subsection{Topology 6}

In this topology, an attempt is made to discover the most prospective areas for construction of PHES plants in Iran. The major criterion that has to be met for a prospective site is the access to perennial water. Thus, areas around all permanent rivers can be assumed as potential areas for discovering suitable locations to build reservoirs. The methodology in this topology adopts the same approach defined by T6 in Table 1. A river is assumed as the lower reservoir and the model explores the surrounding areas for suitable sites to construct the upper reservoir. The applied model in this topology is the same GIS model that is used in T2. The only difference is in the input database used for lower reservoirs. In T2 existing reservoirs are assumed as the lower reservoirs for prospective PHES. While in T6, river ways are divided by points located at $40 \mathrm{~km}$ distance to each other and the location of these points is used in the model as lower reservoirs. 


\subsection{Topology 4}

The intention of T4 is an assessment of the seawater PHES potential in the country. Since in this topology, as reviewed in Table 1, the sea is utilised as the lower reservoir, the whole coastline of the country is divided in points of $20 \mathrm{~km}$ distance from each other and their locations are entered in the model as the potential lower reservoirs. For the upper reservoir, the model is applied to detect the suitable sites. Figure 3 (right) illustrates the algorithm of the GIS model used in T2, T6 and T4.

Scripts of both the models have been written in Python and QGIS 2.18.16 software was used to implement the models.

\subsection{Estimation of energy storage capacity}

Energy storage capacity for a prospective PHES site can be calculated from

$E=\rho \cdot g \cdot h \cdot V \cdot \eta$

Where, $\rho$ is the density of water $\left(1019 \mathrm{~kg} / \mathrm{m}^{3}\right)$, g is acceleration of gravity $\left(9.81 \mathrm{~m} / \mathrm{s}^{2}\right), \mathrm{h}$ is the head, $\mathrm{V}$ is the volume of water in the upper reservoir and $\eta$ is the efficiency of the pump/turbine unit (assumed as 90\%). Conversion of the units from joule to watt-hours may be appropriate for further analyses.

The volume of the upper reservoir in T2 and T6 can be estimated from

$$
V=(A-20000) \cdot d
$$

and for $\mathrm{T} 4$ from

$$
V=(A-2000) \cdot d
$$

Where, $\mathrm{A}$ is the area of the discovered location and $\mathrm{d}$ is the depth of the new reservoir, which was assumed as $20 \mathrm{~m}$ in section $4.2 .20,000 \mathrm{~m}^{2}$ is the area that is considered for civil work and should be subtracted from the total area. In T4 the civil work is considered $2000 \mathrm{~m}^{2}$ since the minimum area in this topology is assumed to be $7000 \mathrm{~m}^{2}$ resulting a minimum $100,000 \mathrm{~m}^{3}$ [37] volume requirement for the prospective new reservoir, while in T2 and T6 the assumed requirement for the reservoir is $1000,000 \mathrm{~m}^{3}$ [35].

\subsection{Constraints: Land occupation and environmental consideration}

The model detects sites that meet the fundamental topographical criteria (head, distance flatness and area restriction) for construction of a PHES plant. Therefore, the results of the model present a theoretical potential for the applied region. To achieve the technical potential several constraints that contain land occupation and environmental consideration are applied to the results to remove infeasible sites. In order to do this, constraints layers are designed based on distance to key features such as inhabited and protected areas and then the overlapping parts of these layers with results layer are eliminated. Considered key features are inhabited areas, transportation infrastructures (railways and roads), protected areas and UNESCO sites. A 500 $\mathrm{m}$ distance from inhabited areas and UNESCO sites and $200 \mathrm{~m}$ from rails and roads also are considered in the constraints layers. Figure 2 illustrates how irrelevant sites that are located in constraints layers are removed from the discovered sites. After applying the constraints the area 
of the sites are calculated again to make sure they still meet the minimum area criterion since in case they have had intersection with constraints layers, some parts of them have been eliminated. The key features and distance from them used for creating the constraints layers are recommended by Gimeno-Gutiérrez and Lacal-Arántegui [37]. In this study the World Database on Protected Areas (WDPA) [48] is used to create the protected landscapes layer. WDPA is a comprehensive database which contains both marine and terrestrial protected areas which make it suitable for this study that includes estimating the potential of seawater PHES in addition to conventional PHES located on land. WDPA comprises different protected zones regulated internationally like Ramsar, UNESCO and World Heritage sites or zones protected by national institutions like National Parks. Although there are PHES plants constructed in protected areas around the world (Dlouhe Strane PHES in a protected area in Czech Republic and Dinorwig PHES in the natural park of Snowdonia in Wales), in this study all protected zones are considered in the protected layer to enable elimination of all detected sites located in sensitive areas in terms of social acceptance or environmental impacts. Inhabited regions, railways and roads dataset have been taken from Geological Survey \& Mineral Exploration of Iran [49] which provides more detailed datasets concerning national data. The inhabited regions layer includes agricultural, commercial, industrial, urban and rural residential sites. Constraints are not applied to T1 since in this topology the second reservoir has already been constructed. Figure 3 summarises the steps of the applied models for the studied topologies.

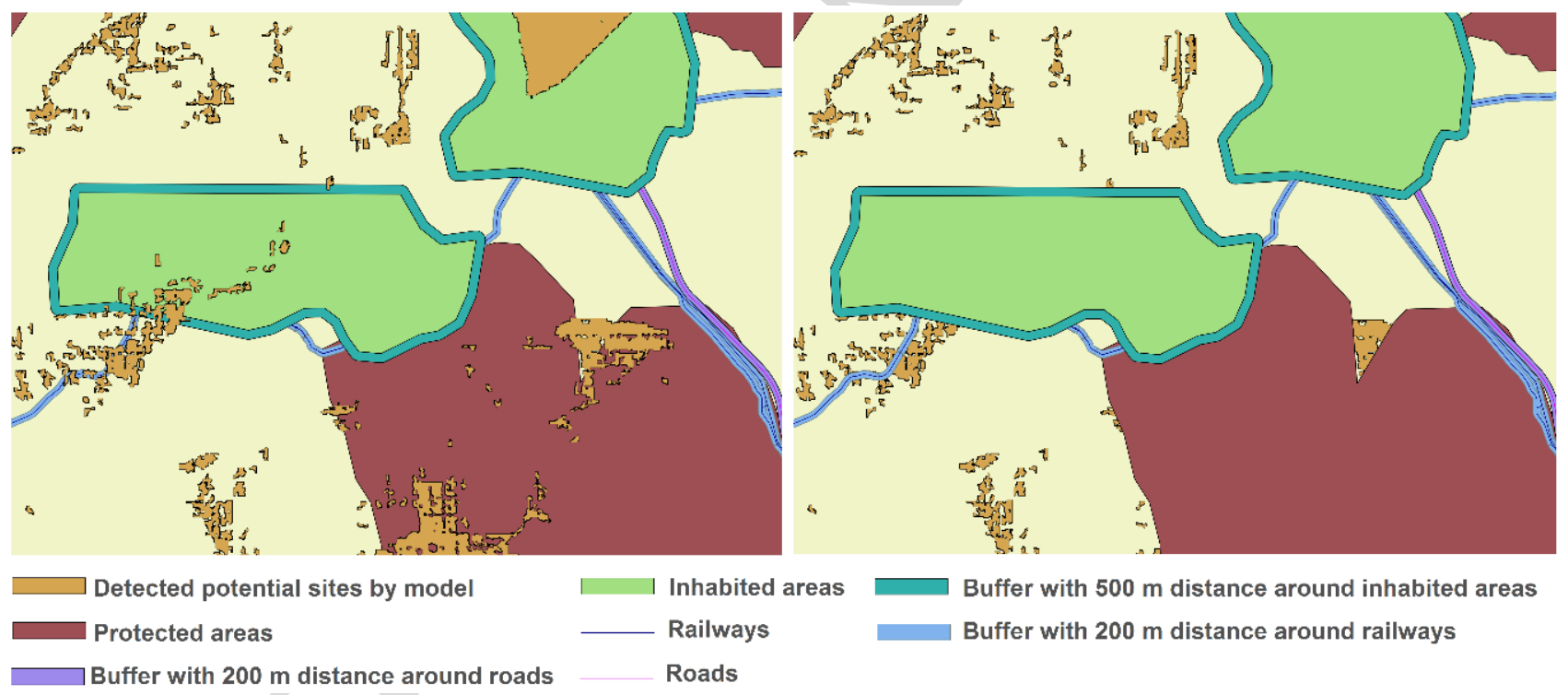

Fig. 2. Elimination of the overlapped part (left) of the discovered site with the constraints layers to achieve the corrected result (right).

\subsection{Multi-criteria analysis - ranking the feasible sites}

A Multi Criteria Decision Making (MCDM) technique is carried out to the feasible sites in order to determine the most suitable sites for construction of the upper reservoir. The MCDM method is commonly used for site selection if there are alternatives with several criteria [50, 51, 52]. In this study, the Technique for Order of Preference by Similarity to Ideal Solution (TOPSIS), which is a widely used and effective MCMD method [53, 54, 55], is used to rank the feasible sites from best to worst. In the TOPSIS technique, the best alternative is the one with the shortest distance from the positive ideal solution and the furthest distance from the 
negative ideal solution. The positive ideal solution is an alternative which consists of all the best values for all criteria whereas the negative ideal solution has the worst value of the criteria. The TOPSIS procedure consist of the following steps:

Step1: Establish a decision matrix (D) which is comprised of all criteria, alternatives and weights of the criteria. The matrix can be presented as follows:

$$
\begin{aligned}
& \text { W1 } \mathrm{W}_{2} \quad \ldots \mathrm{Wn}_{\mathrm{n}} \\
& \begin{array}{llll}
\mathrm{C}_{1} & \mathrm{C}_{2} & \ldots & \mathrm{C}_{\mathrm{n}}
\end{array} \\
& \mathrm{D}=\underset{\mathrm{A}_{2}}{\mathrm{~A}_{2}} \begin{array}{c}
\mathrm{A}_{\mathrm{m}} \\
\mathrm{A}_{\mathrm{m}}
\end{array}\left[\begin{array}{cccc}
\mathrm{x}_{11} & \mathrm{x}_{12} & \cdots & \mathrm{x}_{1 \mathrm{n}} \\
\mathrm{x}_{21} & \mathrm{x}_{22} & \cdots & \mathrm{x}_{2 \mathrm{n}} \\
\vdots & \vdots & \vdots & \vdots \\
\mathrm{x}_{\mathrm{m} 1} & \mathrm{x}_{\mathrm{m} 2} & \cdots & \mathrm{x}_{\mathrm{mn}}
\end{array}\right]
\end{aligned}
$$

Where, $A_{i}=i^{\text {th }}$ feasible alternative, $\mathrm{i}=1,2, \ldots \mathrm{m}$;

$C_{j}=j^{\text {th }}$ criterion $\mathrm{j}=1,2, \ldots \mathrm{n}$

$x_{i j}=$ the performance value of alternative $A_{i}$ for criterion $C_{j}$

$w_{j}=$ the normalised weight of criterion $C_{j}$

$w_{j}=\frac{W_{j}}{\sum W_{j}}, W_{j}=$ the weight of criterion $\mathrm{C}_{j}$

In this study, 7 criteria are selected and the Ratio Estimation procedure [56] is used to weight the criteria. In this method, an arbitrary number is assigned for the weight of the most important criterion and for the other criteria smaller numbers are defined according to their order of

\begin{tabular}{|c|c|c|}
\hline Criterion & Weight & Normalised Weight \\
\hline Head of the site $(\mathrm{h})$ & 10 & 0.25 \\
\hline Area of the site (a) & 8 & 0.2 \\
\hline Distance of the site from the potential lower reservoir (d) & 6 & 0.15 \\
\hline earthquake risk of the site (e) & 5 & 0.125 \\
\hline distance of the site from the high voltage grid $(\mathrm{g})$ & 5 & 0.125 \\
\hline distance of the site from the road (o) & 4 & 0.1 \\
\hline distance of the site from the consumption centre (c) & 2 & 0.05 \\
\hline
\end{tabular}
importance based on experts' opinion. Table 2 presents the criteria and their identified weights.

Table 2. Weights of the selected criteria for the TOPSIS analysis

Step 2: Calculate the normalised decision matrix (R) as follows [57]:

$R=\left(r_{i j}\right)_{m \times n}$

$r_{i j}=\frac{x_{i j}}{\sum_{i=1}^{m}\left(x_{i j}\right)^{2}}$

For attributes which are called benefit attributes in a MCDM analysis, and their higher values lead to more benefit, in this study head and area of the sites are benefit attributes. 
$r_{i j}=1-\frac{x_{i j}}{\sum_{i=1}^{m}\left(x_{i j}\right)^{2}}$

For attributes which are called cost attributes in a MCDM analysis and their higher values increase the cost of the project, therefore their lower values are desirable. In this study, all distances and earthquake risk are cost attributes.

Step 3: Calculate the weighted normalised decision matrix $(V)$ :

$V=\left(v_{i j}\right)_{m \times n}, v_{i j}=w_{j} \times r_{i j}$

Step 4: Determine positive and negative ideal solution:

The positive ideal solution (PIS) and the negative ideal solution (NIS) have respectively the highest and lowest value for each criterion in the weighted normalized decision matrix. Therefore:

PIS : $A^{+}:\left[v^{+}{ }_{1}, \ldots, v^{+}{ }_{j}, \ldots, v^{+}{ }_{n}\right], v^{+}{ }_{j}=\max \left\{v_{i j}\right\}$

$N I S: A^{-}:\left[v^{-}{ }_{1}, \ldots, v^{-}{ }_{j}, \ldots, v^{-} n\right], v^{-}{ }_{j}=\min \left\{v_{i j}\right\}$

Step 5: Calculate the separation (S) of each alternative from PIS and NIS:

$$
\begin{gathered}
S^{+}{ }_{i}=\sqrt{\sum_{j=1}^{n}\left(v_{i j}-v^{+}{ }_{j}\right)^{2}} \\
S^{-}{ }_{i}=\sqrt{\sum_{j=1}^{n}\left(v_{i j}-v^{-}{ }_{j}\right)^{2}}
\end{gathered}
$$

Step 6: Calculate the relative closeness (CP) of each alternative to the PIS

$$
C P_{i}=\frac{\left(S^{-}{ }_{i}\right)}{\left(S^{+}{ }_{i}+S^{-}{ }_{i}\right)}
$$

Step 7: Rank the alternatives according to the relative closeness index

In this study, the TOPSIS procedure is carried out for the feasible sites of each topology separately and it ranks the sites based on their $C P_{i}$ into 8 categories. The results are presented with raster layers in section 7.5. The $\mathrm{CP}$ index ranges between 0 (in case there is an alternative which has the lowest value for all criteria) and 1 (in case there is an alternative which has the highest value for all criteria). 

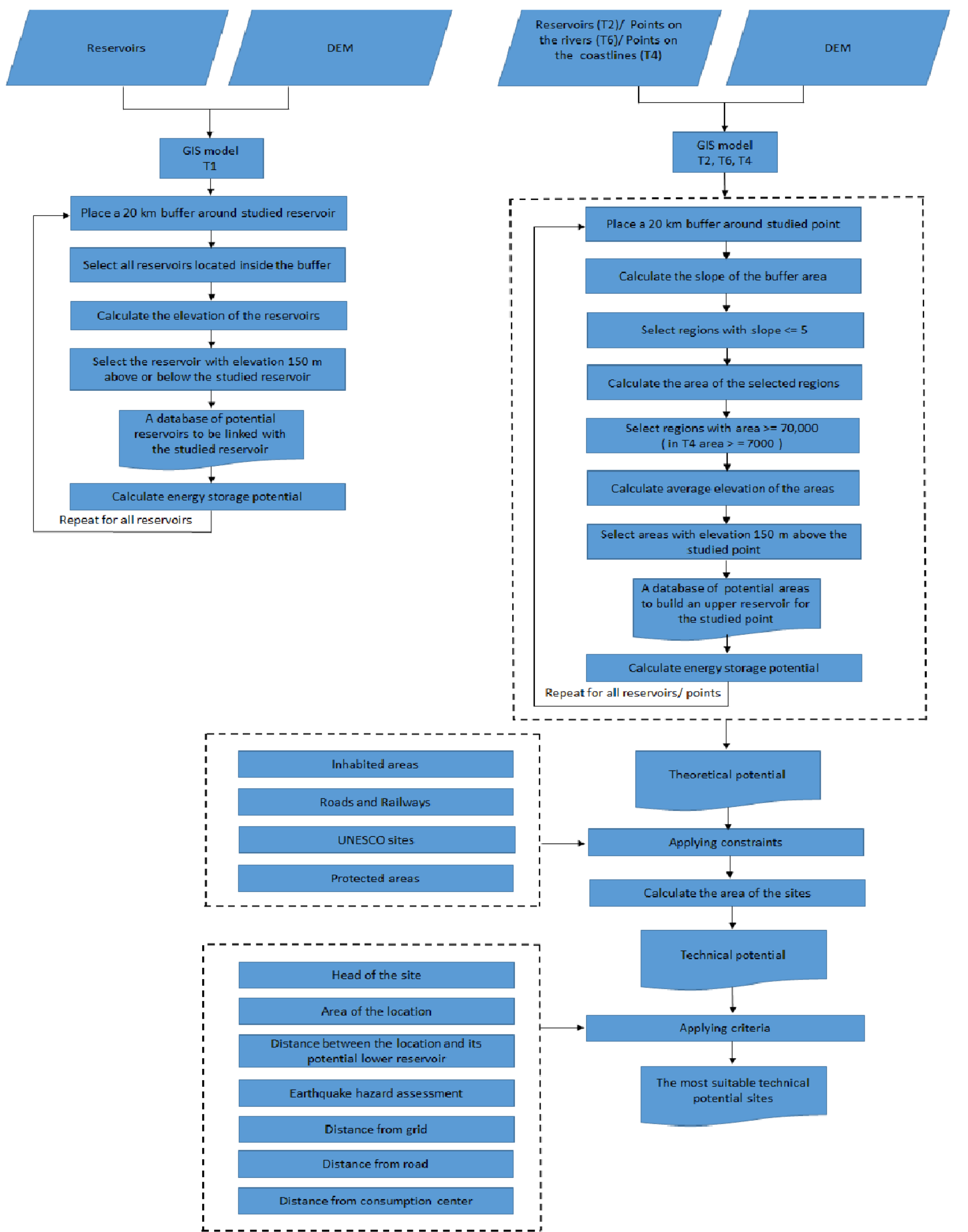

Fig. 3. Flowchart of the GIS model: T1 (left), T2, T4 and T6 (right). Abbreviations: Digital Elevation Model (DEM). 


\section{Data}

\subsection{Reservoirs data}

The reservoirs database used for T1 and T2 comprises 39 major artificial reservoirs created by building a dam on the permanent rivers in Iran. The selected reservoirs for this study were georeferenced manually using Google Earth and their water capacities data were obtained from Iran Water Resources Management Company [27]. Reservoirs with high water storage capacities were selected to ensure availability of enough water all year round, especially during the dry seasons in Iran. In some studies [36,39] reviewed in section 2, lakes are considered as potential reservoirs for PHES plants, but in the present study the option of lakes was discarded, because for the case of Iran, they are not practical waterbodies for the target of this study. Iran has a few perennial lakes, which have already been seriously affected by droughts and environmental crises in the country [58]. The locations of the studied reservoirs are presented in Figure 4.

\subsection{Waterways and coastlines data}

T6 requires a geo-referenced database of the country's rivers with perennial water. Therefore, a data layer containing all waterways of Iran was taken from [63] and all streams and seasonal rivers were removed. Iran's water bodies have been affected by droughts and environmental crises in recent years, thus local data was used to identify latest permanent rivers. Final validation was made by comparing the rivers' maps with the layer data of selected reservoirs in section 6.1. As it can be seen in Figure 4, reservoirs lie in the location of permanent rivers. Regarding T4, the input data is coastlines of the country, $740 \mathrm{~km}$ at the north with the Caspian Sea and $2440 \mathrm{~km}$ at the south with Persian Gulf and Gulf of Oman. The next step is placing points on the rivers and coastlines in order to be entered into the model as the location of the lower reservoir for prospective PHES sites. The defined points are shown in Figure 4.

\subsection{Digital Elevation Model (DEM)}

A Digital Elevation Model (DEM) is required to calculate the elevation and slope of the areas. For this study, digital elevation data provided by the NASA Shuttle Radar Topographic Mission (SRTM) with 3 arc-seconds $(90 \mathrm{~m}$ ) resolution is used [59]. SRTM provides publicly available DEM data on a global scale, which has relatively high vertical accuracy that makes it suitable for this study. A study by Thomas et al. [60] showed $4 \mathrm{~m}$ to $36 \mathrm{~m}$ lower root mean square error for SRTM compared to Advanced Spaceborne Thermal Emission and Reflection Radiometer (ASTER) and Global Multi-resolution Terrain Elevation Data 2010 (GMTED), depending on the investigated place.

Since the SRTM DEM data are available in $5^{\circ} \times 5^{\circ}$ tiles, all tiles covering Iran's territory were merged together and cut by Iran's political borders to form one raster layer for the whole country. The prepared DEM map is presented in Figure 5. 


\section{ACCEPTED MANUSCRIPT}

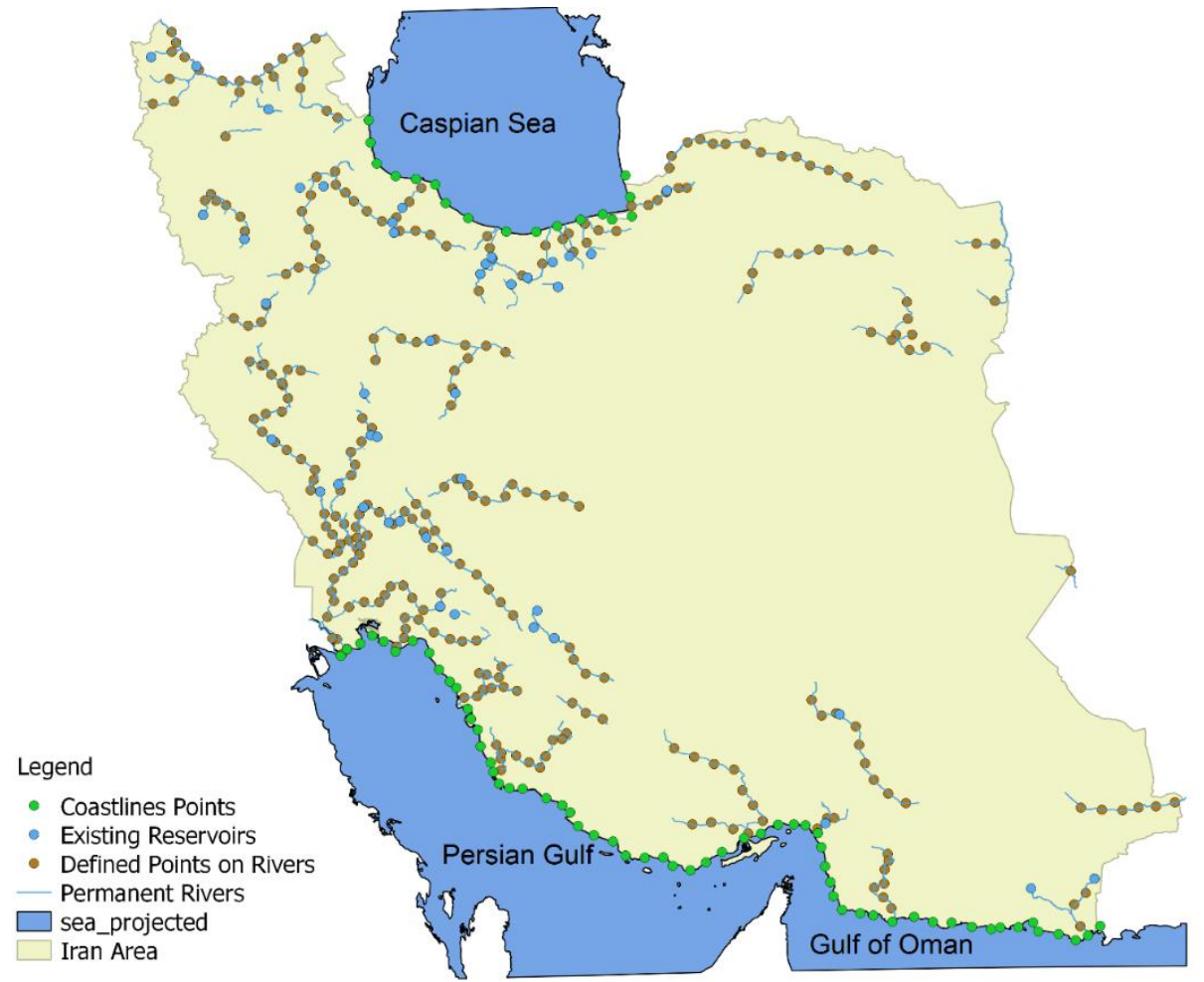

Fig. 4. Location of the existing reservoirs, permanent rivers and defined points on the rivers and coastlines used in the models.

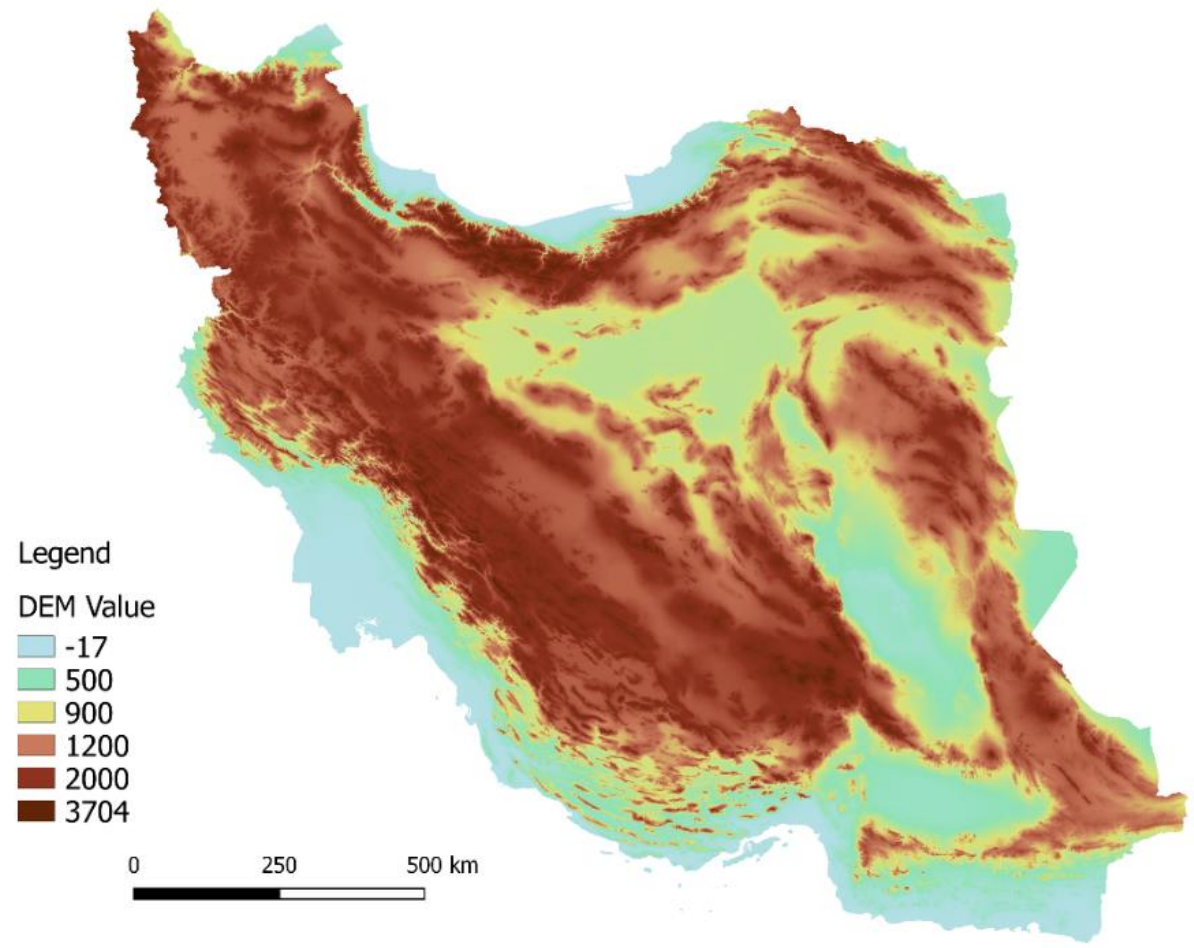

Fig. 5. Digital Elevation Model map of Iran based on SRTM data. 


\section{Results and Discussion}

The results of the theoretical and technical potential of the different topologies are presented in the following subsections: 7.1, 7.2,7.3 and 7.4 present results obtained for the whole country from applying T1, T2, T4 and T6 respectively, while 7.5 shows the distribution of the results across the country

\subsection{Potential of T1}

Among 39 major reservoirs in Iran, two pairs are detected by the GIS model which fulfil the defined constraints in the methodology for transformation to PHES facilities for T1. The details of these sites are presented in Table 3. The first pair are the reservoirs of Iran's only PHES site. Therefore, the site already exists and is not a newly discovered potential but allows a validation of the model. The site has $1040 \mathrm{MW}$ generating capacity, $940 \mathrm{MW}$ pumping capacity and 5.1 GWh storage capacity (considering 3.6 million $\mathrm{m}^{3}$ active capacity of the upper reservoir and the flow rate of $203 \mathrm{~m}^{3} / \mathrm{s}$ that gives a run time of $4.93 \mathrm{~h}$ ) [61]. The second potential site contains two large reservoirs of Iran and potential storage capacity of the site according to Eq. 1 and Eq. 2, is $1396 \mathrm{GWh}$. Although, the estimated potential, due to the large volume of the potential upper reservoir (3140 million $\mathrm{m}^{3}$ ) is huge, the current different features and uses of the upper reservoir (Shahid Abbaspuor) for example, hydropower, water supply, and irrigation make it difficult to assume a potential capacity as significant as the estimated number for the transformation of this reservoir to PHES.

Moreover, the distance between the reservoirs is almost $20 \mathrm{~km}$, the maximum acceptable distance according to the defined constraints in this study, and the head is $178 \mathrm{~m}$ which is not so high that might significantly affect the suitability of the potential site. Therefore, the PHES potential of the country needs to be assessed for other topologies.

Table 3. Potential PHES sites for T1.

\begin{tabular}{|c|c|c|c|c|c|c|c|}
\hline $\begin{array}{l}\text { Site } \\
\text { no. }\end{array}$ & $\begin{array}{l}\text { Upper Reservoir } \\
\text { Name }\end{array}$ & $\begin{array}{c}\text { Upper Reservoir } \\
\text { Latitude, Longitude }\end{array}$ & $\begin{array}{l}\text { Lower Reservoir } \\
\text { Name }\end{array}$ & $\begin{array}{l}\text { Lower Reservoir } \\
\text { Latitude, Longitude }\end{array}$ & $\begin{array}{l}\text { Upper Reservoir } \\
\text { Volume } \\
\left(\text { million } \mathbf{m}^{\mathbf{3}}\right)\end{array}$ & $\begin{array}{c}\text { Head } \\
(\mathbf{m})\end{array}$ & $\begin{array}{c}\text { Distance Between } \\
\text { Reservoirs } \\
(\mathbf{k m})\end{array}$ \\
\hline 1 & Siah Bishe Upper & $36.1989,51.3210$ & Siah Bishe Lower & $36.2251,51.3055$ & 3.7 & 520 & 3.15 \\
\hline 2 & Shahid Abbaspour & $32.1174,49.6166$ & Masjed Soleyman & $32.0280,49.4002$ & 3140 & 178 & 19.48 \\
\hline
\end{tabular}

\subsection{Potential of $\mathrm{T} 2$}

The results of $\mathrm{T} 2$ show that in $20 \mathrm{~km}$ search buffer for each reservoir, there are several suitable areas to construct upper reservoirs. Although, the area with the highest storage capacity potential should be selected, the distance of the area from the reservoir is a key parameter in the site selection approach, since it can highly affect the costs of the project, which partly scale with length of the required penstock for the PHES site. Therefore, the maximum potential is calculated in 4 buffer areas around the existing reservoir with radius of 5, 10, 15 and $20 \mathrm{~km}$. In this respect, for every reservoir the site with the highest storage capacity in each buffer is 
selected. Figure 6 shows total detected sites and feasible sites after applying constraints for all reservoirs in 4 explored buffers.

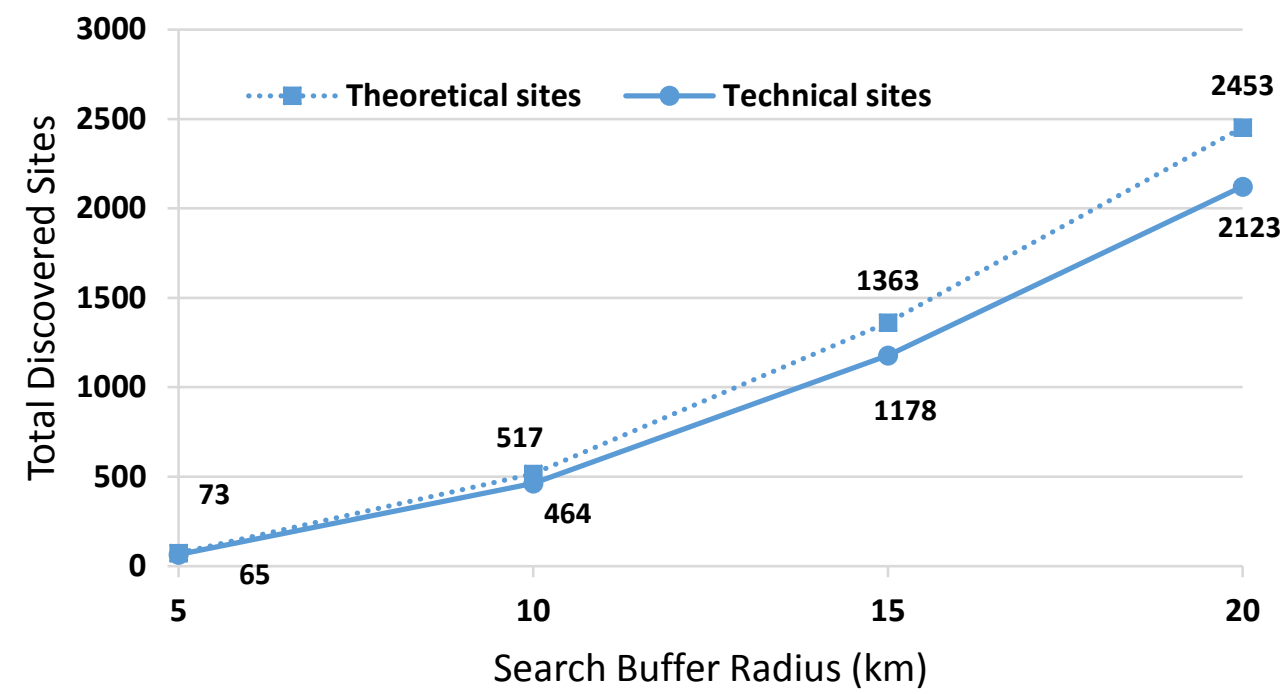

Fig. 6. Total discovered areas and feasible sites for $\mathrm{T} 2$ in 4 search buffers

As shown in Figure 6, the model discovers more potential sites with increasing radius of the search area. Increasing the radius from 5 to $10 \mathrm{~km}$, results in an increase in the number of detected areas from 73 to 517. Larger buffer areas with 15 and $20 \mathrm{~km}$ radius result in 1363 and 2453 suitable sites respectively. Applying the constraints decreases the number of suitable sites and results to 2123 feasible sites in $20 \mathrm{~km}$ distance from the reservoirs. Applying constraints does not reduce the number of sites significantly since only parts of a site which overlaps with the constraints layers is eliminated and if the remaining part still satisfies the minimum area of $70,000 \mathrm{~m}^{2}$, the site is considered feasible. For all reservoirs, the detected and feasible site with the highest storage capacity in each buffer area is selected to estimate the theoretical and technical potential. Finally, for each existing reservoir, the optimum site resulting from the TOPSIS method is selected. The analysis of one of the existing reservoirs for $\mathrm{T} 2$ is shown in Figure 7. The reservoir is Molasadra located in southwest Iran and constructed on the Kor River with a water capacity of 440 million $\mathrm{m} 3$. The model detected 72 potential sites, which meet the specified parameters to form PHES facilities with the reservoir. The details of the selected sites are presented in Table 4.

Table 4. Details of the labelled areas in Figure 7.

\begin{tabular}{|c|c|c|c|c|c|c|c|c|c|}
\hline $\begin{array}{l}\text { No. of Labeled } \\
\text { Area in Figure } 7\end{array}$ & $\begin{array}{c}\text { Area } \\
\left(\mathbf{m}^{2}\right)\end{array}$ & $\begin{array}{c}\text { Head } \\
(\mathbf{m})\end{array}$ & $\begin{array}{c}\text { Storage } \\
\text { Capacity } \\
(\mathbf{G W h})\end{array}$ & $\begin{array}{c}\text { Distance } \\
\text { from the } \\
\text { Reservoir } \\
(\mathbf{k m})\end{array}$ & $\begin{array}{c}\text { Earthquake } \\
\text { risk }\end{array}$ & $\begin{array}{c}\text { Distance } \\
\text { from the } \\
\text { grid }\end{array}$ & $\begin{array}{l}\text { Distance } \\
\text { from the } \\
\text { road }\end{array}$ & $\begin{array}{c}\text { Distance } \\
\text { from the } \\
\text { consumption } \\
\text { centre }\end{array}$ & $\begin{array}{c}\text { Relative } \\
\text { closeness } \\
\text { index } \\
\text { (CP) }\end{array}$ \\
\hline 1 & 81,904 & 162 & 0.5 & 4.6 & 0.25 & 73 & 2 & 46 & 0.41 \\
\hline 2 & 795,640 & 160 & 6 & 7.4 & 0.25 & 66 & 0.63 & 64 & 0.45 \\
\hline 3 & $5,294,513$ & 160 & 42 & 11.5 & 0.25 & 72 & 8 & 62 & 0.38 \\
\hline 4 & 561,627 & 553 & 15 & 12.3 & 0.25 & 64 & 5 & 53 & 0.56 \\
\hline
\end{tabular}



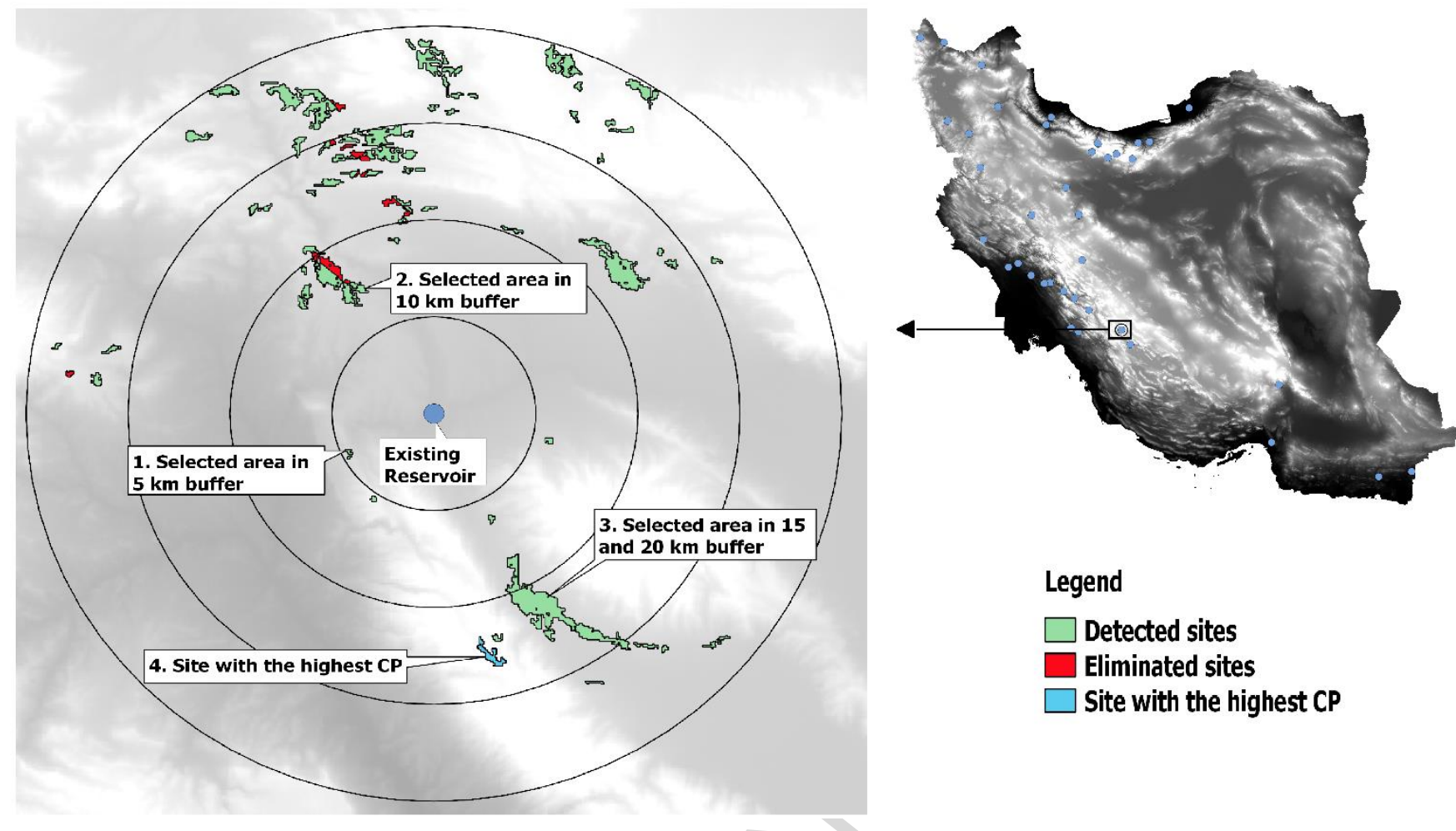

\section{Legend}

$\square$ Detected sites

Eliminated sites

Site with the highest $C P$

Fig. 7. Total discovered and selected areas for Molasadra reservoir, a sample of the process of site selection.

The sites labelled 1 and 2, are the sites with the highest potential capacity among all feasible sites in a buffer of $5 \mathrm{~km}$ and $10 \mathrm{~km}$, respectively. The site no. 3 is the area, which provides the highest potential among all detected sites for the reservoir. The distance between the area (the centre of the area) and the reservoir is $11.5 \mathrm{~km}$. Therefore, the selected area can be considered in both 15 and $20 \mathrm{~km}$ buffers. It can be seen that the selected sites with the highest storage potential in all buffers have a relatively low head. High head sites are typically more cost effective because they provide an equivalent amount of energy with smaller reservoirs (Eq. 1). Moreover, since they require less volume of stored water, they are more desirable for regions like Iran where the topography provides high heads while freshwater supply can be a challenging issue. In this study, the intention of the storage potential calculation process is to estimate the highest potential of PHES schemes in the country. In order to determine the optimum site, a site selection approach based on TOPSIS model is adopted to evaluate and compare important characteristics of all feasible sites though a MCDM process. The results of applying the TOPSIS model show that the site no. 4 has the highest relative closeness index (CP) and it can provide the optimum location for construction of the upper reservoir for the studied existing reservoir. The visualisation of the sites no. 3 and no. 4 in Google Earth is presented in Figure 8.

In this topology, the CP index of the feasible sites (2123 sites in total) range from 0.89 in "Karoon 3" reservoir in the south of Iran to 0.26 in "Mollasadra" reservoir, while about $92 \%$ of the sites have a CP index more than 0.5 that indicates there are a high number of potential sites with a feasibility higher than medium value. 


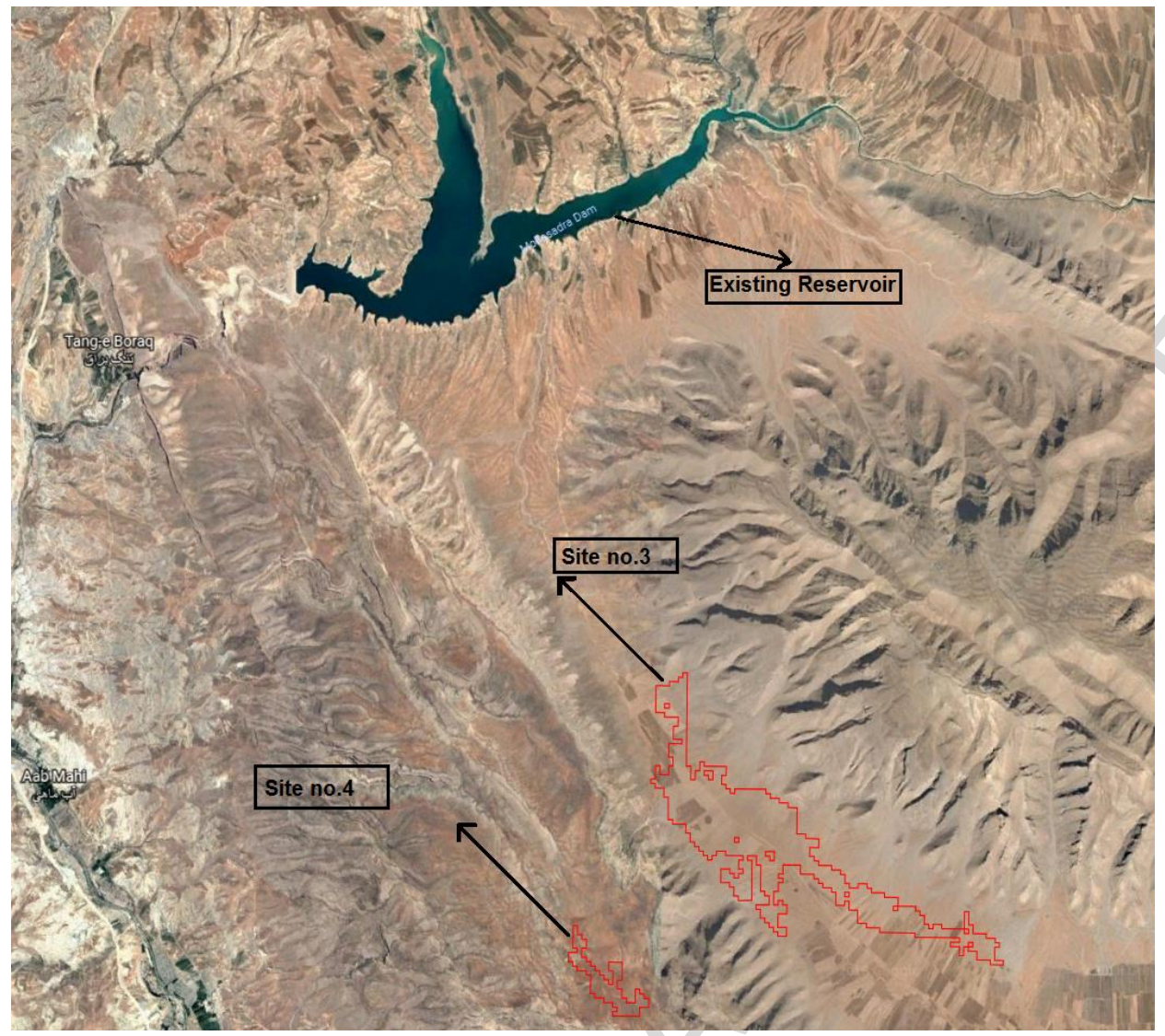

Fig. 8. The visualisation of the site no. 3 and no. 4, with the highest storage capacity and the optimum site with the highest CP index (see Tab. 3 and Fig. 7) for Molasadra reservoir.

Figure 9 shows total energy storage and average head for the selected sites in each buffer area for all 39 studied reservoirs and for both theoretical and technical sites. The overall potential increases significantly as the buffer radius increases towards $20 \mathrm{~km}$, the maximum acceptable distance defined for this study. Increasing the distance from 5 to $10 \mathrm{~km}$, results in an increase in theoretical potential capacity from 44 to $517 \mathrm{GWh}$, and a further increase in distance to 15 $\mathrm{km}$, results in $1342 \mathrm{GWh}$ of storage capacity. The largest buffer area with $20 \mathrm{~km}$ radius offers a theoretical potential of $2192 \mathrm{GWh}$. Moreover, there is an increase in average head of the selected areas with increasing the buffer area, from $246 \mathrm{~m}$ in $5 \mathrm{~km}$ distance to $463 \mathrm{~m}$ in $20 \mathrm{~km}$ distance.

The application of the constraints layers to the theoretical potential results in a reduction of 509 GWh storage capacity and loss of 330 sites. Figure 9 shows that the technical potential follows the same trend as the theoretical potential but with lower storage capacity and average head in all buffer areas. 


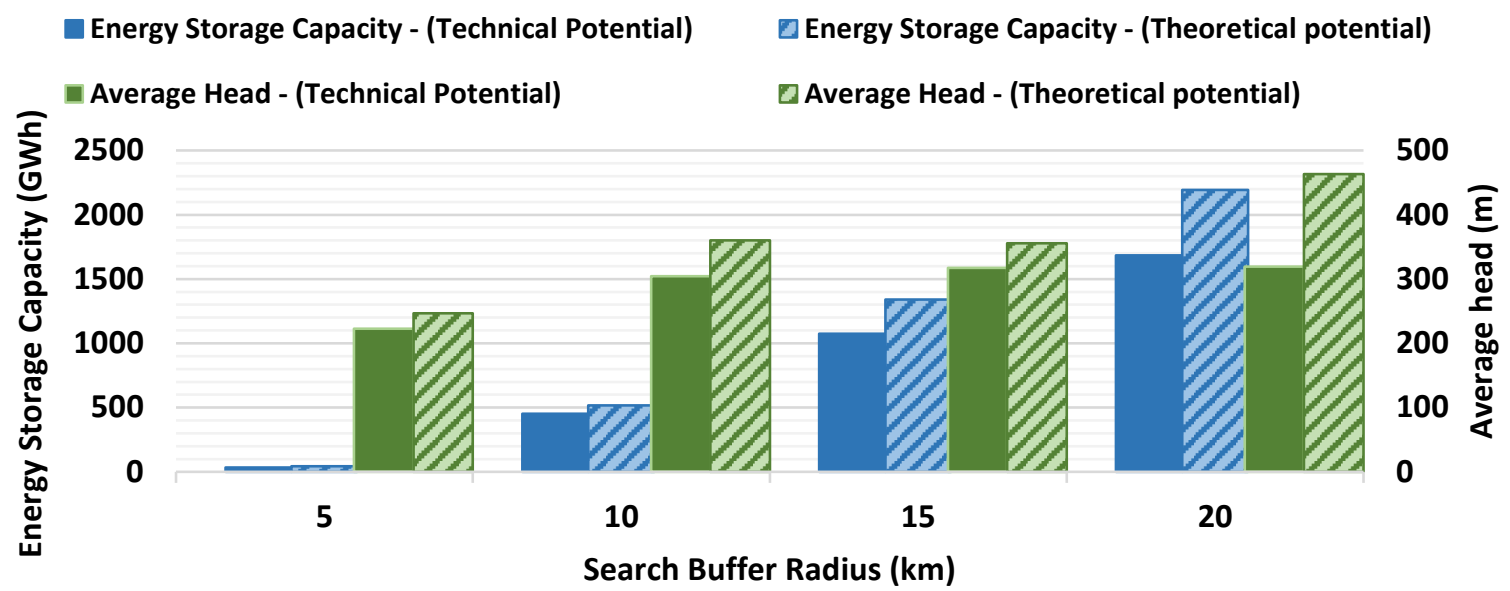

Fig. 9. Total energy storage capacity and average head for theoretical and technical sites in T2.

\subsection{Potential of T6}

In this topology, a $20 \mathrm{~km}$ buffer area around 276 points on the permanent rivers of Iran that account for $346,656 \mathrm{~km} 2$ of the country's land were investigated. Locations of the points are assumed as potential lower reservoirs and the model seeks suitable sites to host the upper reservoirs. The analysis results in a total theoretical potential of $3279 \mathrm{GWh}$ from 165 discovered sites and $3105 \mathrm{GWh}$ technical potential from 163 feasible sites. The estimated technical potential is considerable and 609 times higher than the current PHES capacity (5.1 GWh) in the country. T6 offers a considerable higher potential compared to T2, as a result of an increase in the studied points from 39 in T2 to 276 in T6, which leads to a higher number of potential sites. Total technical and technical energy storage capacity in the 4 distance categories for T2 and T6 is presented in Figure 10.

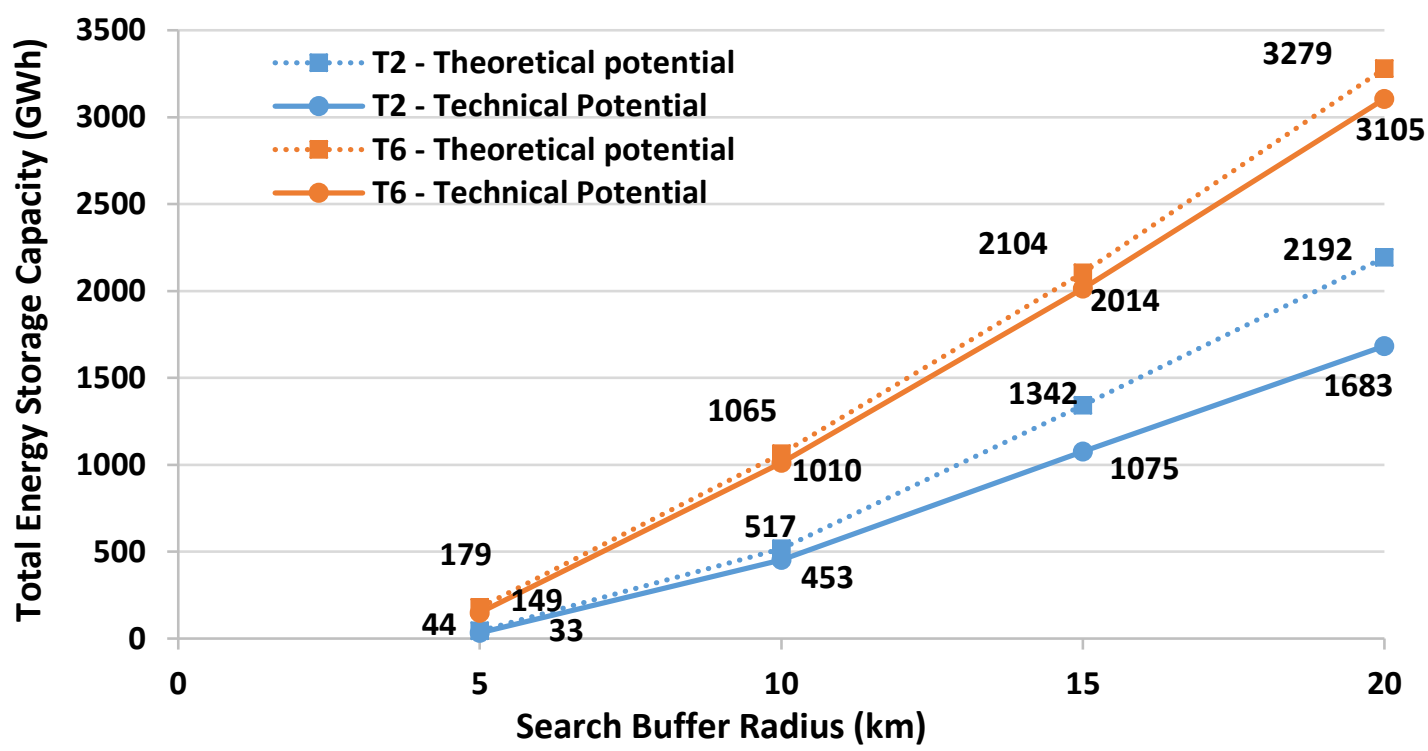

Fig. 10. Total theoretical and technical energy storage capacity in 4 buffer areas for T2 and T6. 
In all buffer areas, T6 possess a higher storage capacity and as the buffer radius grows the difference between the energy storage capacities in two topologies increases. The reason is attributed to the number of sites for the topologies in each category. The number of the sites for each buffer area in both T2 and T6 are shown in Figure 11.

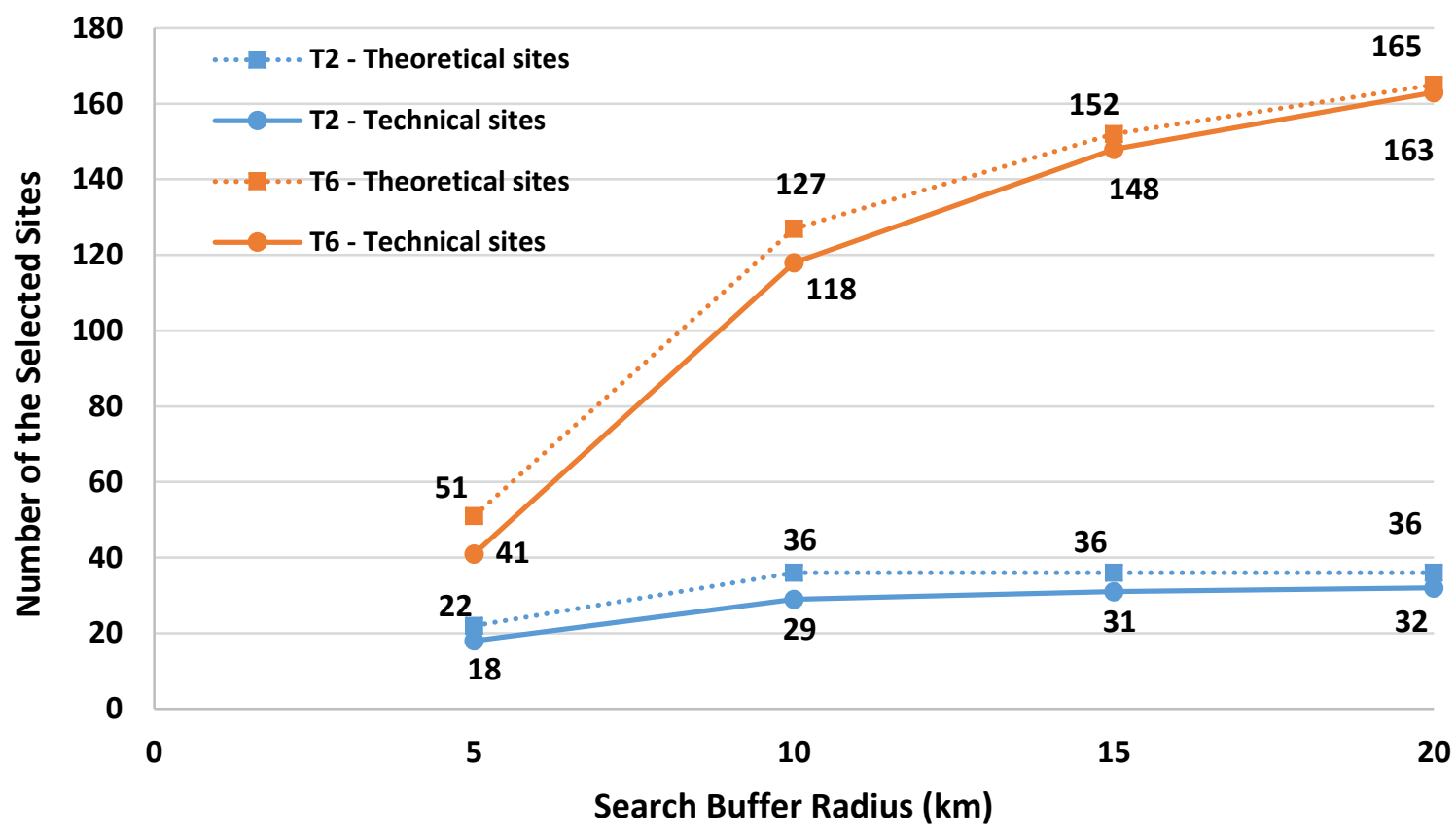

Fig. 11. The number of selected sites in theoretical and technical potential in 4 buffer areas for T2 and T6.

Figure 11 indicates that the difference between storage capacities in T2 and T6 are consistent with the increase in the number of sites. The number of sites is limited to the number of studied points, since for each studied point, which is assumed as a potential lower reservoir, one site among all discovered areas that has the highest energy storage capacity is selected as a potential upper reservoir to form a PHES site. For T2, the maximum number of selected sites is 39, which is the number of existing reservoirs. Figure 11 shows that for 22 of the reservoirs, the model detects suitable sites in $5 \mathrm{~km}$ distance, but for the rest of the reservoirs the search area needs to be increased to a $10 \mathrm{~km}$ distance. By increasing the search area more than $10 \mathrm{~km}$, the model captures areas with higher storage capacities. However, for 3 of the reservoirs the model did not find any suitable areas even in a $20 \mathrm{~km}$ distance and 4 of them lost their detected sites by applying the constraints, thus the total number of the feasible sites is 32 . For T6, 276 is the maximum number of possible sites and Figure 11 shows 163 detected feasible sites in $20 \mathrm{~km}$ distance. It indicates that Iran's topology is suitable for building substantial PHES capacities, since for $59 \%$ of the studied points on the rivers, there are suitable locations to construct PHES plants. The CP index in T6 ranges from 0.91 in the southwest of the country to 0.15 in the south of the country. Although the maximum CP index in T6 is higher than the corresponding value in $\mathrm{T} 2$, only $1.5 \%$ of the sites have a $\mathrm{CP}$ index more than 0.5 while in $\mathrm{T} 2$, sites with more than medium CP index value account for $92 \%$ of the sites. The results of the TOPSIS method on two of the studied points are presented in Figure 12. The feasible sites are ranked into 8 categories based on their CP index. Figure 12 indicates the importance of applying a multi 
criteria analysis to integrate economical sensitivity into the topographical assessment to determine the most prospective areas. Figure 12 shows that a large part of the searched area for the southern point is discovered as feasible site but all the sites offer a CP index less than medium value. On the other hand, the studied point in the southwest of the country have far fewer feasible sites but presenting the highest value of the $\mathrm{CP}$ index.

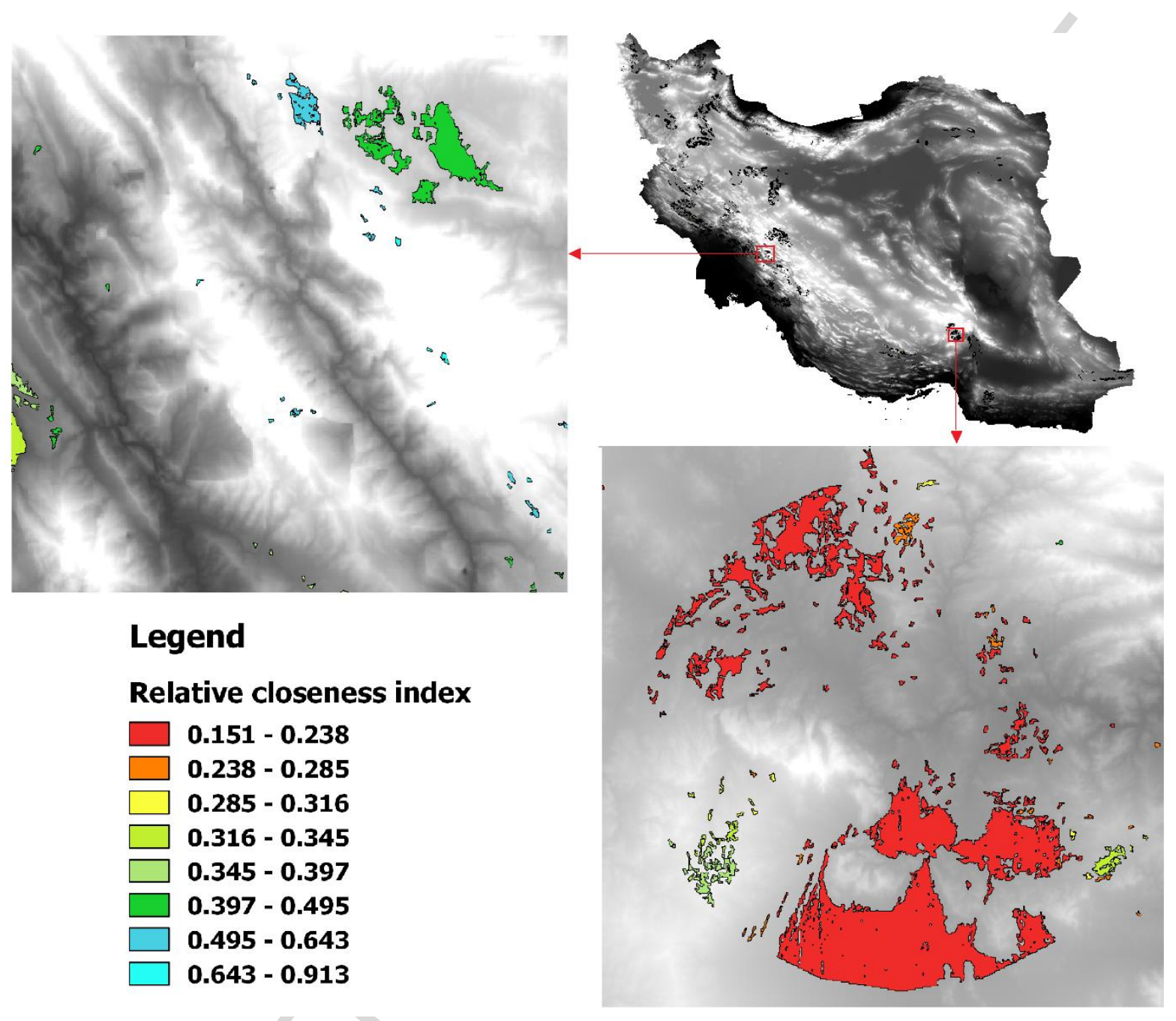

Fig. 12. Ranking the feasible sites of two studied points for $\mathrm{T} 6$ according to the value of their relative closeness index $(\mathrm{CP})$, resulting from the TOPSIS analysis

\subsection{Potential of T4}

T2 and T6 present substantial potential for construction of PHES plants in Iran. However, the cost and environmental concerns associated with the construction of two reservoirs in T6 and supplying large volume of freshwater in both T2 and T6 motivates the assessment of potential for seawater PHES as an unconventional PHES plants which requires only one reservoir and no freshwater. The developed model in this study evaluates the topography of the whole coastline of the country of more than $3000 \mathrm{~km}$ length, $740 \mathrm{~km}$ in the north at the Caspian Sea and $2440 \mathrm{~km}$ in the south at the Persian Gulf and Gulf of Oman. The results show a total technical potential of $320 \mathrm{GWh}$, with contribution of the Gulfs' area of $88 \%$. The results indicate that Gulfs' coastline provide a larger potential compared to the northern coastal area. 
Moreover, since the northern coastal area is more populated and environmentally more sensitive than the southern coastal areas, a larger part of its discovered sites is rejected by applying the constraints layer; in numbers $38 \%$ in comparison to $25 \%$ rejection for the Gulfs' theoretical potential. The results of the TOPSIS analysis for both coastline areas are presented in Figure 18 which indicate the Persian Gulf provides sites with the higher ranks.

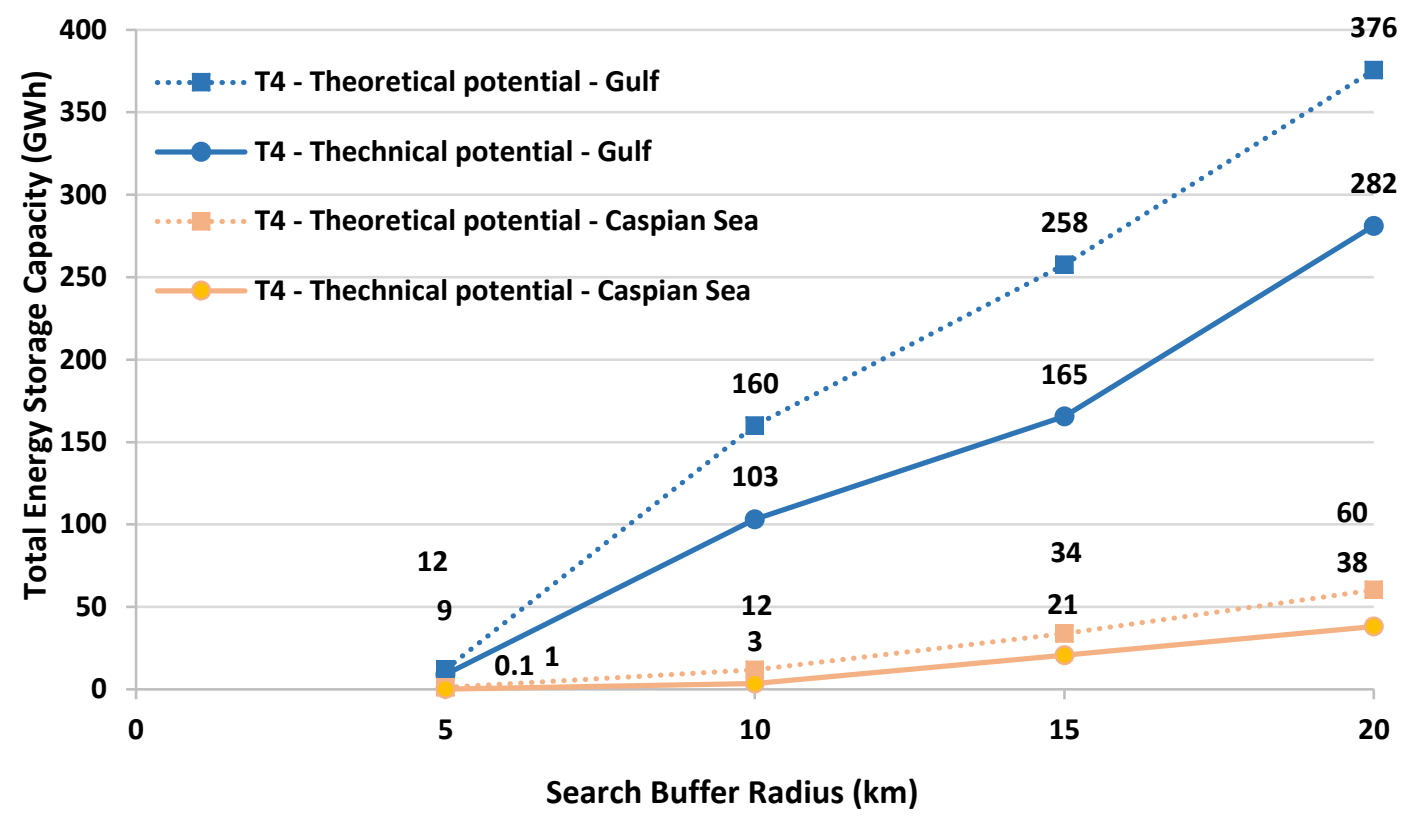

Fig. 13. Theoretical and technical potential of the two coastal areas of Iran.

\subsection{Regional Potential}

This section represents the distribution of prospective sites for PHES across the country. Political subdivision of Iran is in the form of provinces, but a study by Ghorbani et al. [64] model Iran in nine regions according to the country's grid structure, electricity demand and renewable energies potential in the provinces, in order to study a transition for Iran's power system towards a zero emission system based on renewables. Figure 14 shows nine modelled regions of Iran and Figure 15 presents the potential of each region for T2, T6 and T4. Figure 15 indicates that regions 6, 2, 7 and 1 have the highest potential for PHES with 1352, 972, 959 and $754 \mathrm{GWh}$, while the rest of the country presents significantly less potential. The reason for regions 5,8 and 9 is more attributed to the access of these regions to water resources, rather than the topography of the regions. As the studied topologies in this research focusses on surrounding areas of the permanent rivers, reservoirs and coastlines in the country and these regions have limited access to these water resources (see Fig. 4). However, region 3 and 4 have substantial water resources but a large part of their potential areas was eliminated by applying the constraints since these regions are densely populated and contain societally and environmentally sensitive locations. Although, in this study the major criterion for a potential PHES site was access to perennial water, a research carried out by Lu et al. [40] and Blakers [65] indicate that the potential of off-river PHES sites in Australia is 67 TWh which is 150 times more than the required storage capacity for a $100 \%$ renewables-based power system in 
Australia. The studies argue that water could be provided from nearby water resources, groundwater or micro-catchments. Similar topologies which do not require direct access to water bodies and only seek proper locations in hills and mountains could significantly increase the number of prospective PHES sites in the dry regions of Iran. However, supplying a large volume of freshwater remains a challenging issue for these topologies. Figures 16, 17 and 18 present the country level of the TOPSIS analysis on the results' layers of T2, T6 and T4 respectively. In order to do this, the country was divided into $20 \mathrm{~km} \times 20 \mathrm{~km}$ squares, the distance between the studied points in this study, and the weighted average of the CP index for feasible sites of each grid cell was calculated. Although T6 provide $3105 \mathrm{GWh}$ PHES potential compared to $1683 \mathrm{GWh}$ in T2, Figure 16 shows that the feasible sites in T2 especially in region 6 present much higher ranks in the TOPSIS analysis. Therefore, since the identified criteria in the TOPSIS model highly affect the cost and feasibility of the sites, T2 offers more costeffective and suitable sites. The results in T4 show $320 \mathrm{GWh}$ technical potential for seawater PHES in the country, of which the southern coastlines especially at the Persian Gulf provide the major part that contributes mainly to the potential of region 7 , while it does not have a substantial effect on the potential of region 9, the other coastal region.

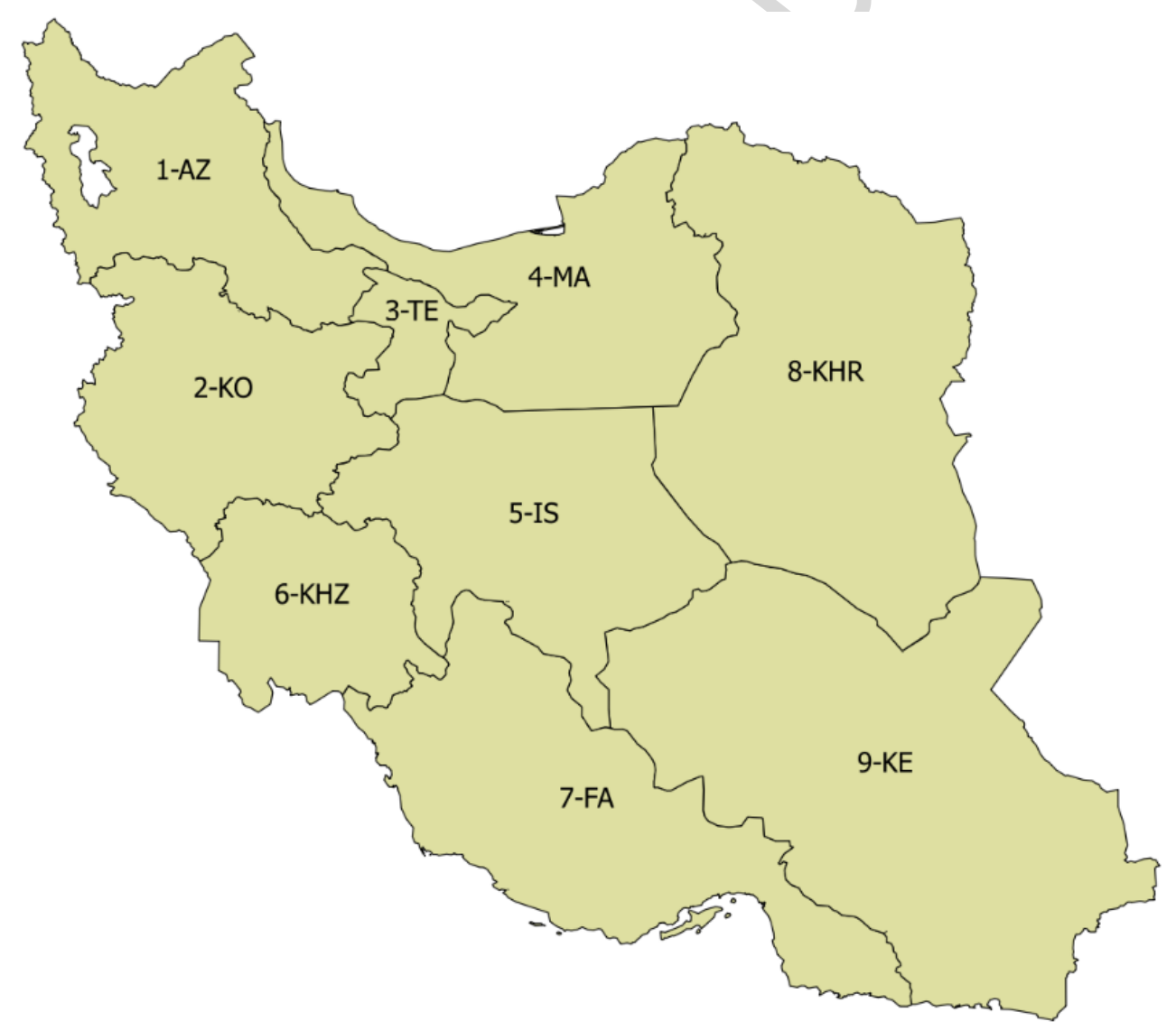

Fig. 14. Iran's subdivision into nine modelled regions [64]. The name of the region is abbreviated with the name of the province with the highest electricity consumption among all corresponding provinces of the region. AZ: Azerbaijan, KO: Kurdistan, TE: Tehran, MA: Mazandaran, IS: Isfahan, KHZ: Khuzestan, FA: Fars, KHR: Khorasan, KE: Kerman. 


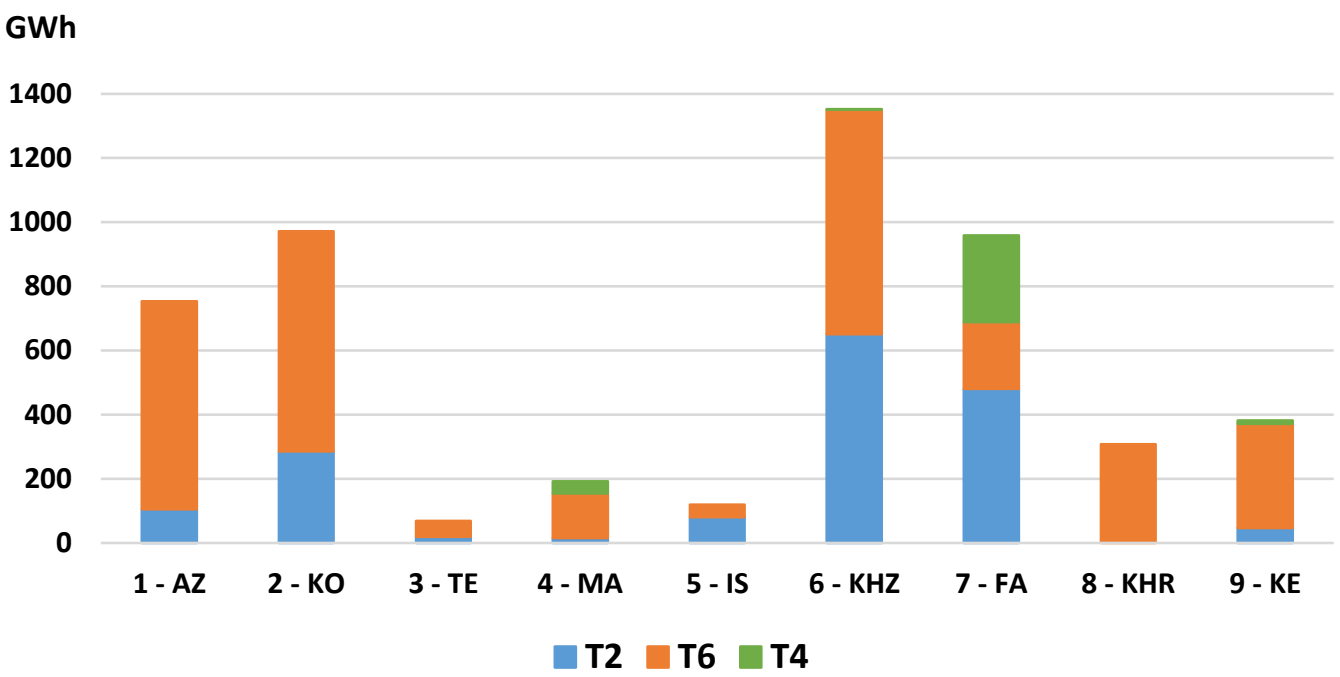

Fig.15 Regional breakdown of PHES technical potential (in GWh) for T2, T6 and T4.

Although the studied topologies only focus on the areas with available water resource, the discovered potential is substantial for covering the storage demand of a power system totally run by variable renewable energies in Iran. [23]. The estimated PHES potential in this study of $5108 \mathrm{GWh}$ (total potential for T2, T6 and T4) is comparable to the results of a recent study of Ghorbani et al. [23], which projects a storage demand of about 51,877 GWh (thereof 1638 GWh for diurnal and 50,239 GWh for long-term storage) for the country's power system in 2050. While all electricity is supplied by RE, especially variable solar PV and wind energy. The study analyses a transition pathway for Iran's power system from the current energy system based on fossil fuels to a sustainable system totally run by RE in 2050 . The proposed power system which is more cost-effective than the current system, not only provides the electricity demand of the power system, but also the electricity required by the desalination and PtG sectors to supply water demand and non-energetic gas demand of the country. The results show that the least cost storage mix of the proposed system consists of $1437 \mathrm{GWh}$ utility-scale batteries and 17 GWh of PHES to cover short-term storage demand, while $42 \mathrm{GW}_{\text {el }}$ RE-based $\mathrm{PtG}$ technology provides seasonal storage as well as the country's non-energetic gas demand. Therefore, the total estimated potential of $5108 \mathrm{GWh}$ in the present study is about 3.5 times more than the total projected short-term storage demand (1454 GWh). Although batteries would be the most cost-effective storage solution for short-term storage demand due to its fast technology development and ongoing cost reduction, its availability and potential in the country needs to be taken into consideration. Lithium-ion batteries that are considered in this study may have limited resources in the future, while Iran has a favourable topography for conventional PHES and seawater PHES according to the present study and also the country has a long history in construction of dams and hydropower facilities. Therefore, part of the required battery capacity can be substituted by PHES systems, which can be constructed with locally available materials and technologies. Moreover, PHES can have a long lifetime up to 100 years, while batteries need to be replaced several times during this time. Therefore, PHES would be a very feasible complementary storage technology to support batteries in the future. 


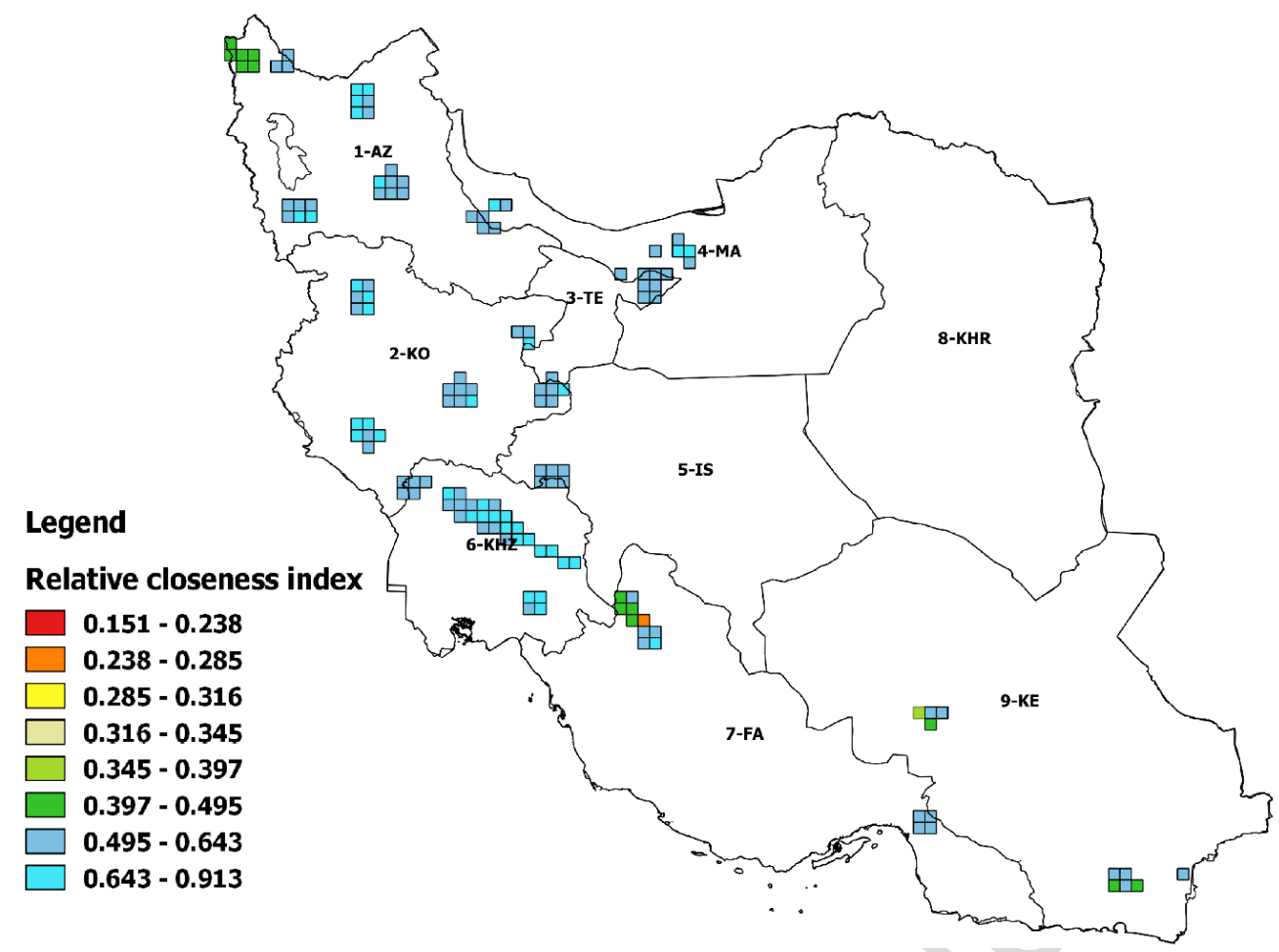

Fig. 16. Ranking the discovered feasible sites for $\mathrm{T} 2$, according to the value of their relative closeness index (CP), resulting from the TOPSIS analysis

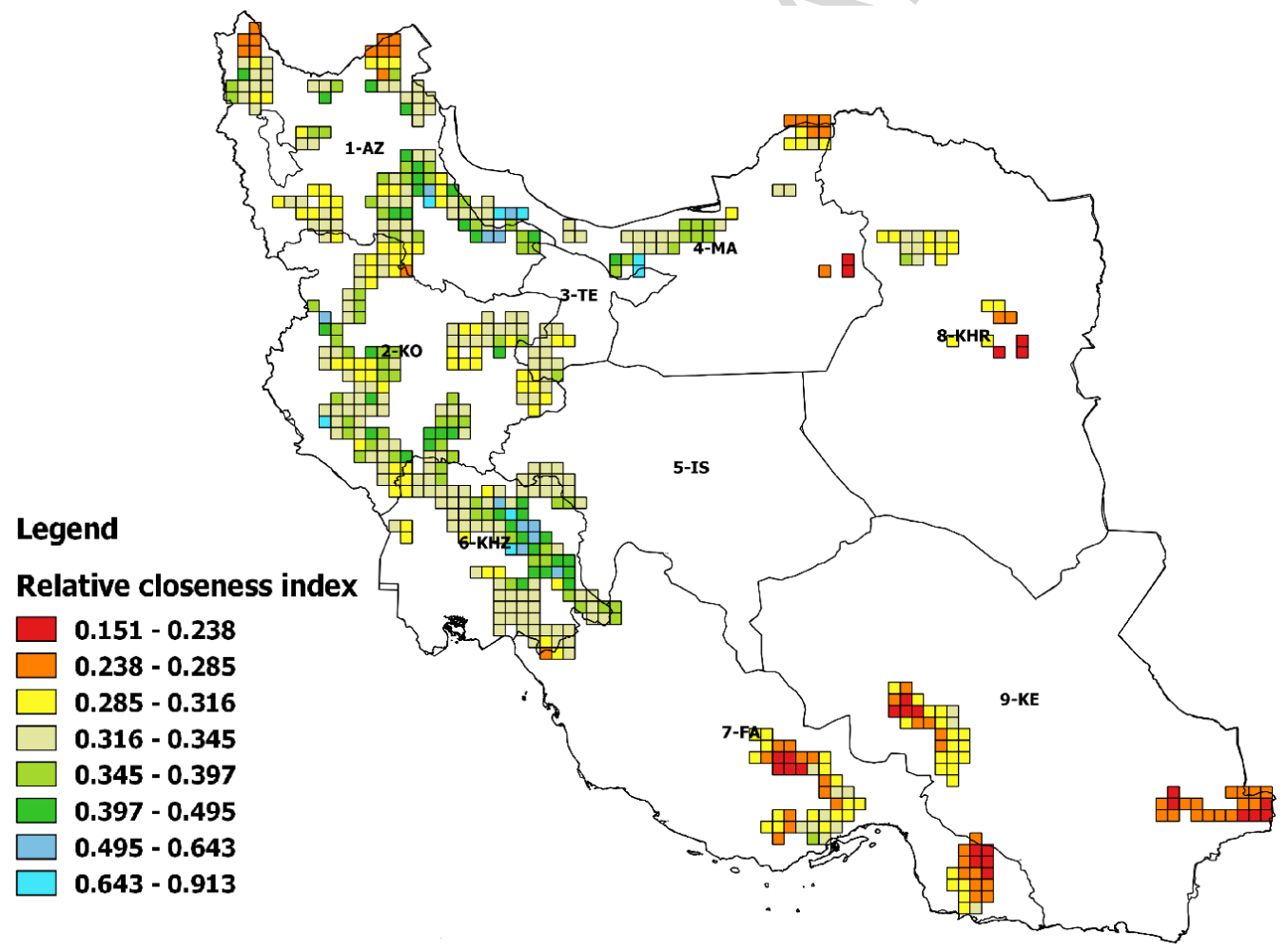

Fig. 17. Ranking the discovered feasible sites for T6, according to the value of their relative closeness index (CP), resulting from the TOPSIS analysis 


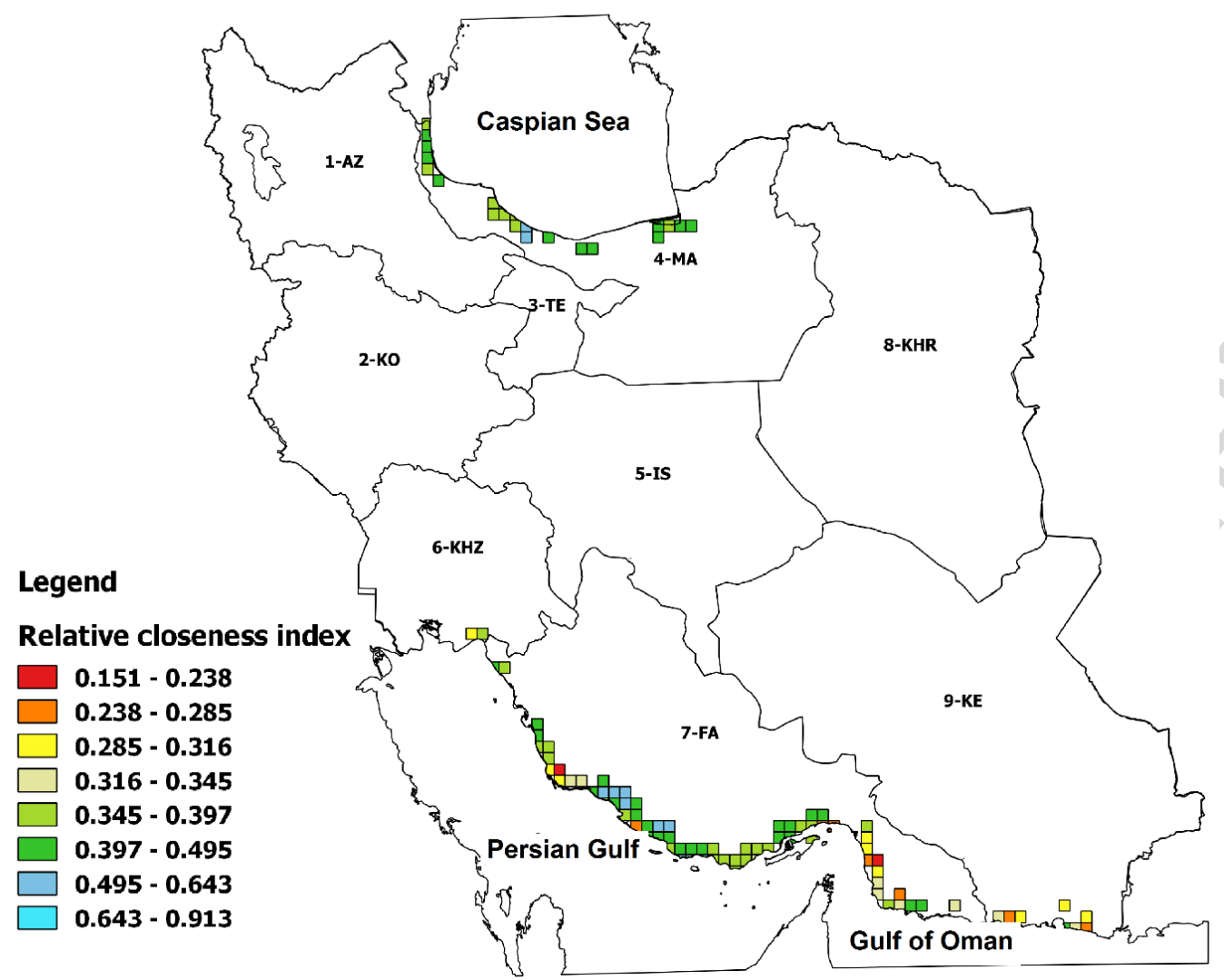

Fig. 18. Ranking the discovered feasible sites for $\mathrm{T} 4$, according to the value of their relative closeness index (CP), resulting from the TOPSIS analysis

\section{Conclusions}

This study is the first assessment to estimate the potential of PHES for 4 different topologies including seawater PHES topology, on a country level. The assessment is carried out by a GISbased model, which is applicable to any selected country. In this study, Iran was selected as the case study country and the topography of the surrounding areas of its existing reservoirs, permanent rivers and coastlines were analysed to discover potential sites for construction of PHES plants. The strict constraints layers including all categories of the World Database on Protected Areas (WDPA) were applied to the detected sites to eliminate infeasible areas. Finally, to evaluate the feasible sites, a TOPSIS model was carried out to rank the sites according to their relative closeness index.

The results show a total theoretical potential of 1396, 2192, 3279 and $436 \mathrm{GWh}$ for T1, T2, T6 and $\mathrm{T} 4$ respectively, while a maximum $20 \mathrm{~km}$ distance is considered for the distance between the potential upper and lower reservoirs. Application of the constraints resulted in a total technical potential of 1396, 1683, 3105 and $320 \mathrm{GWh}$ for T1, T2, T6 and T4 respectively .For shorter distances, the potential decreased drastically, since fewer sites can be captured by the model. Moreover, the discovered sites have lower heads and smaller areas which results in lower energy storage capacity potential. For the $5 \mathrm{~km}$, the shortest considered distance in this study, the technical potential of T1, T2 ,T6 and T4 decreased to $0,33,149$ and $9.1 \mathrm{GWh}$, respectively. The intention of $\mathrm{T} 1$ and $\mathrm{T} 2$ is using the existing reservoirs for transformation to PHES facilities, which would have less environmental and economic burdens due to the 
existence of both reservoirs (T1) or one of them (T2). However, for T6 more potential areas are discovered for PHES facilities in Iran that offers more alternatives for the site selection process. The TOPSIS analysis shows the discovered sites for T2 present higher ranked locations which offer more cost-effective and feasible sites. T4 analyses the potential of seawater PHES, an innovative PHES plant approach that is suitable for regions where supplying large volume of freshwater is a challenging issue. The country's southern coastal areas contribute to $88 \%$ to the total technical potential of T4 and sites at the Persian Gulf presents higher ranked sites.

The results of this study could be used as an initial map for a realistic and practical site selection process in Iran. Moreover, the model can be applied to other countries and an estimate of the global potential of PHES facilities could be derived. Iran is highly endowed with solar and wind energy and recent studies $[23,62]$ showed that the country could build a sustainable and affordable power system totally based on RE which is dominated by solar and wind energy. This $100 \%$ RE system requires the support of storage technologies along with other solutions to balance the supply and demand hourly, daily and all year round. Due to ongoing cost decline, batteries are more likely to play an important role to cover hourly and daily storage demands. On the other hand, PHES is operated in a similar manner as batteries to cover diurnal storage demands, but PHES also has the advantage of locally available potential and less scarce material and technologies in comparison to batteries. The results of this study show that Iran has a high potential for PHES sites. The total estimated technical potential for T2, T6 and T4 is about 1000 times higher than the existing PHES capacity in the country and the results are comparable with the country's estimated storage demand in the future. Thus, decision makers can consider this mature and utility-scale storage technology for a sustainable future energy system based on RE in Iran.

\section{Acknowledgements}

The first author gratefully acknowledges "Marjatta ja Eino Kollin" and "Maa-ja Vesitekniikan Tuki" foundations for their valuable scholarships. The authors thank Roberto Lacal Arántegui, Joint Research Center of the European Commission, Petten, for the valuable discussions. The authors would also like to thank Manish Ram for proofreading, Kristina Sadovskaia for providing the Iranian grid map.

\section{References}

[1] UNFCCC- United Nations Framework Convention on Climate Change, "Paris Agreement," $21^{\text {st }}$ Conference of the Parties, 2015. [Online]. Available: http://unfccc.int/files/essential_background/convention/application/pdf/english_paris_agreeme nt.pdf. (Accessed: June 11, 2018).

[2] Ram M., Bogdanov D., Aghahosseini A., Oyewo A.S., Child M., Fell H.-J., Breyer C. Global Energy System based on $100 \%$ Renewable Energy - Power Sector. Study by Lappeenranta University of Technology and Energy Watch Group. Lappeenranta. Berlin. November 2017. Available: https://goo.gl/ghDikW.

[3] Breyer Ch., Bogdanov D., Aghahosseini A., Gulagi A., Child M., Oyewo A.S., Farfan J., Sadovskaia K., Vainikka P. Solar Photovoltaics Demand for the Global Energy Transition in the 
Power Sector. Progress in Photovoltaics: Research and Applications. 2018; 26 (8), 505-523

[4] Brown T. W., Bischof-Niemz T., Blok K., Breyer Ch., Lund H., Mathiesen B.V. Response to 'Burden of proof: A comprehensive review of the feasibility of $100 \%$ renewable-electricity systems'. Renewable and Sustainable Energy Reviews. 2018; 92, 834-847.

[5] Renewable Energy Policy Network for the 21st Century (REN21) - Renewables 2018 Global Status Report, Paris, 2018. Available: http://www.ren21.net/wp-content/uploads/2018/06/178652_GSR2018_FullReport_web_-1.pdf.

[6] Greenpeace International, energy [r]evolution - A sustainable world energy outlook, Amsterdam, 2015. [Online] Available :

http://www.greenpeace.org/international/Global/international/publications/climate/2015/Energ y-Revolution-2015-Full.pdf.

[7] Jacobson M.Z., Delucchi M.A., Bauer Z.A.F., Goodman S.C., Chapman W.E., Cameron M.A., Bozonnat C., Chobadi L., Clonts H.A., Enevoldsen P., et al. 100\% Clean and Renewable Wind, Water, and Sunlight All-Sector Energy Roadmaps for 139 Countries of the World. Joule. 2017; 1: $108-121$.

[8] Sgouridis S., Csala D., Bardi U. The sower's way: quantifying the narrowing net-energy pathways to a global energy transition. Environmental Research Letters. 2016; 11: 94009.

[9] Blakers A., Lu B., Stocks M. 100 \% renewable electricity in Australia. Energy. 2017; 133: 471482.

[10] Guittet M., Capezzali M., Gaudard L., Romerio F., Vuille F., Avellan F. Study of the drivers and asset management of pumped-storage power plants historical and geographical perspective. Energy. 2016; 111: 560-579.

[11] Aghahosseini A. and Breyer Ch. Assessment of Geological Resource Potential for Compressed Air Energy Storage in Global Electricity Supply. Energy Conversion and Management. 2018; 169: 161-173.

[12] Götz M., Lefebvre J., Mörs F., McDaniel Koch A., Graf F., Bajohr S., Reimert R., Kolb T. Renewable Power-to-Gas: A technological and economic review. Renewable Energy. 2016; 85: 1371-1390.

[13] The Gurdian. South Australia turns on Tesla's 100MW battery: 'History in the making',2017. [Online] Available: https://www.theguardian.com/australia-news/2017/dec/01/south-australiaturns-on-teslas-100mw-battery-history-in-the-making (Accessed June 7, 2018).

[14] Yang C., Jackson R.B. Opportunities and barriers to pumped-hydro energy storage in the United States. Renewable and Sustainable Energy Reviews. 2011; 15: 839-844.

[15] The stoRE Project - Facilitating energy storage to allow high penetration of intermittent renewable energy:stoRE - Final Publishable Report , Munich, 2014. Available: https://goo.gl/z4cyTJ.

[16] Farfan J. and Breyer Ch. Structural changes of global power generation capacity towards sustainability and the risk of stranded investments supported by a sustainability indicator. Journal of Cleaner Production. 2017; 141, 370-384.

[17] Kousksou T., Bruel P., Jamil A., Rhafiki T.El, Zeraouli Y. Energy storage: Applications and challenges. Solar Energy Materials \& Solar Cells. 2014; 120: 59-80.

[18] European Comission - Energy storage: the role of electricity, Brussels, 2017. Available: https://goo.gl/DGKrBY.

[19] Rehman S., Al-hadhrami LM., Alam M. Pumped hydro energy storage system : A technological review. Renewable and Sustainable Energy Reviews. 2015; 44: 586-598.

[20] Portero U., Velázquez S. and Carta J.A. Sizing of a wind-hydro system using a reversible hydraulic facility with seawater. A case study in the Canary Islands. Energy Conversion and 
Management. 2015; 106: 1251-1263.

[21] Fujihara T, Imano H, Oshima K. Development of pump turbine for seawater pumped storage power plant. Hitachi Review. 1998; 47: 199-202.

[22] Katsaprakakis D.A., Christakis D.G., Stefanakis I., Spanos P. and Stefanakis N. Technical details regarding the design, the construction and the operation of seawater pumped storage systems. Energy. 2013; 55: 619-630.

[23] Ghorbani N., Aghahosseini A., Breyer Ch. Transition towards a 100\% Renewable Energy System and the Role of Storage Technologies : A Case Study of Iran. Energy Procedia. 2017; 135: 23-36.

[24] Garcia CC. Testing a GIS-based methodology for optimal location of Pumped Storage power plants in Norway, Master Thesis, Norwegian University of Scince and Technology, 2013. Available: https://goo.gl/cfPsVL.

[25] Iran Power Generation and Transmission Company (TAVANIR). Detailed statistics of Iran's Power Industry,Tehran, 2015. Available: https://goo.gl/8NKYnh [in Persian].

[26] Kiyani Haftlang k. The Book of Iran: A Survey of the Geography of Iran. Tehran: Ministry of Culture and Islamic Guidance; 2003.

[27] Iran Water Resources Management Company. Statistics of Dams in the Country. [Online] Available: http://daminfo.wrm.ir/fa/dam/stats (Accessed :May 19, 2018) [in Persian].

[28] Islamic Republic News Agency. Dams: Structures for managing crisis or the reason of the crisis, 2016. [Online] Available: http://www.irna.ir/fa/News/82307274 (Accessed: May 25, 2018) [in Persian].

[29] Zamaneh News. Electricity Generation of Dams in Iran is 5\% of the Total Capacity, 2015. [Online] Available: https://www.radiozamaneh.com/226688 (Accessed May 18, 2018) [in Persian].

[30] Moshiri S., Lechtenböhmer S. Sustainable Energy Strategy for Iran. Wuppertal Institute for Climate, Environment and Energy, Berlin, 2015. Available: https://goo.gl/WS5vDG.

[31] Alamdari P., Nematollahi O., Mirhosseini M. Assessment of wind energy in Iran : A review. Renewable and Sustainable Energy Reviews. 2012; 16: 836-860.

[32] Alamdari P., Nematollahi O., Alemrajabi AA. Solar energy potentials in Iran: A review. Renewable and Sustainable Energy Reviews. 2013; 21: 778-788.

[33] Rogeau A., Girard R., Kariniotakis G. A generic GIS-based method for small Pumped Hydro Energy Storage (PHES) potential evaluation at large scale. Energy. 2017; 197: 241-253.

[34] Soha T., Munkacsy B., Harmat A., Csontos C., Horvath G., Laszlo T., et al. GIS-based assessment of the opportunities for small-scale pumped hydro energy storage in middlemountain areas focusing on artificial landscape features. Energy. 2017; 141: 1363-1373.

[35] Lacal Arántegui R., Fitzgerald N., Leahy P. Pumped-hydro energy storage: potential for transformation from single dams. Joint Research Center of the European Commission, Petten, 2012.

[36] Hall DG., Lee RD. Assessment of Opportunities for New United States Pumped Storage Hydroelectric Plants Using Existing Water Features as Auxiliary Reservoirs. Idaho National Laboratory, Idaho, 2014. Available: https://goo.gl/C4SGR9.

[37] Gimeno-Gutiérrez M., Lacal-Arántegui R. Assessment of the European potential for pumped hydropower energy storage storage potential. Joint Research Center of the European Commission, Petten, 2013. Available: https://goo.gl/DTSNLs.

[38] Fitzgerald N., Lacal R., Mckeogh E., Leahy P. A GIS-based model to calculate the potential for transforming conventional hydropower schemes and non-hydro reservoirs to pumped 
hydropower schemes. Energy. 2012; 41: 483-490.

[39] Lu X., Wang S. A GIS-based assessment of Tibet's potential for pumped hydropower energy storage. Renewable and Sustainable Energy Reviews. 2017; 69: 1045-1054.

[40] Lu B., Stocks M., Blakers A., Anderson K. Geographic information system algorithms to locate prospective sites for pumped hydro energy storage. Applied Energy. 2018; 222: 300-312.

[41] Connolly D., Maclaughlin S., Leahy M. Development of a computer program to locate potential sites for pumped hydroelectric energy storage. Energy. 2010; 35: 375-381.

[42] Ahmadi H., Shamsai A. Preliminary Site Selection of Pumped Storage. AUT Journal of Modeling and Simulation. 2009; 41: 25-32.

[43] Akinyele D.O., Rayudu R.K. Review of energy storage technologies for sustainable power networks. Sustainable Energy Technologies and Assessments. 2014; 8: 74-91.

[44] Pimentel D., Berger B., Filiberto D., Newton M., Wolfe B., Karabinakis B., et al. Water resources: agricultural and environmental issues. Bioscience. 2004; 54: 909-918.

[45] Katsaprakakis D.A., Christakis D.G. Seawater pumped storage systems and offshore wind parks in islands with low onshore wind potential. A fundamental case study. Energy. 2014; 66: 470-486.

[46] Ioakimidis C.S. and Genikomsakis K.N. Integration of Seawater Pumped-Storage in the Energy System of the Island of São Miguel (Azores). Sustainability. 2018; 10: 3438

[47] KotiugaW., Hadjian S., King M., Al-Hadhrami L.M., Arif M.,Al-Soufi K.Y. Pre-feasibility study of a 1000 MW seawater pumped storage plant in Saudi Arabia. Hydrovision international conference, Denver, July 23;2013.

[48] Protected Planet, World Database on Protected Areas (WDPA). [Online] Available: https://www.protectedplanet.net/country/IR. [Accessed: 08-Nov.-2018]

[49] Geological Survey \& Mineral Exploration of Iran. Tehran, https://gsi.ir/en.

[50] Sánchez-Lozano J. M., García-Cascales M. S. and Lamata M. T. Identification and selection of potential sites for onshore wind farms development in Region of Murcia, Spain. Energy. 2014; 73: 311-324.

[51] Sánchez-Lozano J. M., Teruel-Solano J., Soto-Elvira P. L. and García-Cascales M. S. Geographical Information Systems (GIS) and Multi-Criteria Decision Making (MCDM) methods for the evaluation of solar farms locations: Case study in south-eastern Spain. Renewable and Sustainable Energy Reviews. 2013; 24: 544-556.

[52] Villacreses, G., Gaona, G., Martínez-Gómez, J.and Jijón, D. J. Wind farms suitability location using geographical information system (GIS), based on multi-criteria decision making (MCDM) methods: The case of continental Ecuador. Renewable Energy. 2017; 109: 275-286.

[53] Yildirim V., Memisoglu T., Bediroglu S., Colak H.E. Municipal solid waste landfill site selection using Multi-Criteria Decision Making and GIS: case study of Bursa province. Journal of Environmental Engineering and Landscape Management. 2018;26:107-19.

[54] Caliskan E. Planning of environmentally sound forest road route using GIS \& S-MCDM. Šumarski list. 2017; 141:583-91.

[55] Jozaghi A., Alizadeh B., Hatami M., Flood I., Khorrami M., Khodaei N., Tousi E.G. A Comparative Study of the AHP and TOPSIS Techniques for Dam Site Selection Using GIS: A Case Study of Sistan and Baluchestan Province, Iran. doi:10.20944/preprints201810.0773.v1

[56] Malczewski, J. GIS and multicriteria decision analysis. New York: John Wiley and Sons; 1999

[57] Yue, Z. A method for group decision-making based on determining weights of decision makers using TOPSIS. Applied Mathematical Modelling. 2011; 35: 1926-1936. 
[58] Hossein Mardi A., Khaghani A., Macdonald AB., Nguyen P., Karimi N., Heidary P., et al. The Lake Urmia environmental disaster in Iran : A look at aerosol pollution. Science of the Total Environment. 2018; 633: 42-49.

[59] The CGIAR Consortium for spatial Information (CGIAR-CSI). The NASA Shuttle Radar Topographic Mission (SRTM) 90m Digital Elevation Data. United States Geological Survey, Reston. [Online] Available: http://srtm.csi.cgiar.org (Accessed February 10, 2018).

[60] Thomas J., Joseph S., Thrivikramji K.P., Arunkumar K.S. Sensitivity of digital elevation models : The scenario from two tropical mountain river basins of the Western Ghats, India. Geoscience Frontiers. 2014; 5: 893-909.

[61] Iran Water\& Power Resources Development Company.Tecnical specifications of the Siah Bishe site. [Online] Available: https://goo.gl/ZtHVwP (Accessed May 18, 2018) [in Persian].

[62] Aghahosseini A., Bogdanov D., Ghorbani N., and Breyer Ch. Analysis of 100\% renewable energy for Iran in 2030: integrating solar PV, wind energy and storage. International Journal of Environmental Science and Technology. 2018; 15: 17-36.

[63] DIVA-GIS. [Online] Available: http://www.diva-gis.org (Accessed: Feb. 25, 2018).

[64] Ghorbani N., Aghahosseini A., Breyer Ch. Assessment of a power system fully based on renewable energy for Iran by 2050 - Comparison with the current policy scenario, submitted for publication.

[65] Blakers A., Stocks, M., Lu B., Anderson K., Nadolny A. An atlas of pumped hydro energy storage. Australian National University. Canberra. September 2017. Available: https://goo.gl/LrcYXV. 
- Comprehensive new methodology for PHES potential assessment developed

- Technical potential of PHES in Iran is 1000 times higher than the existing capacity

- Southwest of Iran provides the highest PHES potential and the most suitable sites

- Substantial potential for covering short-term storage demand in 2050 